\title{
Towards the Next-generation Drug Delivery Vehicle: Synthesis of a Dendrimer with Four Orthogonally Reactive Groups
}

\section{Experimental}

\section{General Procedures}

Chemicals were purchased from Aldrich and Acros and used without further purification. All solvents were ACS grade and used without further purification. NMR spectra were recorded on a Varian Mercury $300 \mathrm{MHz}$ or Inova $500 \mathrm{MHz}$ spectrometer in $\mathrm{CDCl}_{3}$, $\mathrm{MeOH}-\mathrm{d}_{4}$, or $\mathrm{CDCl}_{3}: \mathrm{MeOH}-\mathrm{d}_{4}(10: 1)$. All mass spectral analyses were carried out by the Laboratory for Biological Mass Spectrometry at Texas A\&M.

\section{Experimental Procedures}

Intermediate 2. A solution of BOC-ON (30.0 g, $122 \mathrm{mmol})$ in THF (150 mL) was added dropwise to an ice-bath cooled solution of 3,3'-diaminodipropylamine $(8.5 \mathrm{~mL}$, $60.9 \mathrm{mmol})$ and DIPEA $(30 \mathrm{~mL}, 172 \mathrm{mmol})$ in THF $(150 \mathrm{~mL})$. After the addition was complete, the reaction mixture was stirred for $4 \mathrm{~h}$ at room temperature, and the solvent was then removed by reduced-pressure evaporation. The residue was dissolved in dichloromethane and extracted with $5 \% \mathrm{NaOH}(\mathrm{aq})$. The organic layer was dried over $\mathrm{MgSO}_{4}$ and then evaporated under vacuum. The resulting thick oil was precipitated from dichloromethane and petroleum ether to give $2(17.1 \mathrm{~g}, 85 \%)$ as a white solid.

${ }^{1} \mathrm{H}$ NMR (300 MHz, $\left.\mathrm{CDCl}_{3}\right) \delta 3.21$ (q, 4H), $2.66(\mathrm{t}, J=6.5 \mathrm{~Hz}, 4 \mathrm{H}), 1.66(\mathrm{~m}, 4 \mathrm{H}), 1.44$ $(\mathrm{s}, 18 \mathrm{H}) ;{ }^{13} \mathrm{C} \mathrm{NMR}\left(75 \mathrm{MHz}, \mathrm{CDCl}_{3}\right) \delta 156.26,79.13,47.54,39.05,29.86,28.55$; MS (ESI-TOF) calcd for $\mathrm{C}_{16} \mathrm{H}_{33} \mathrm{~N}_{3} \mathrm{O}_{4} 331.25$, found $332.27(\mathrm{M}+\mathrm{H})^{+}$.

Intermediate 3. A reaction solution of $2(5.0 \mathrm{~g}, 15.1 \mathrm{mmol})$ and DIPEA $(8.0 \mathrm{~mL}, 46.0$ $\mathrm{mmol})$ in THF $(150 \mathrm{~mL})$ was cooled in a salt/ice-bath before cyanuric chloride $(2.78 \mathrm{~g}$, $15.1 \mathrm{mmol}$ ) was added. The solution was stirred for $2 \mathrm{~h}$ at low temperature. Subsequently, 2-(2-aminoethoxy)ethanol $(3.0 \mathrm{~mL}, 30.0 \mathrm{mmol})$ and methanol $(25 \mathrm{~mL})$ were added to the reaction mixture. The reaction solution was stirred for $24 \mathrm{~h}$. Following removal of the salts by filtration, the solution was evaporated under vacuum. The residue was dissolved in dichloromethane and washed with brine. The organic layer was dried over $\mathrm{MgSO}_{4}$ and then evaporated under vacuum. The crude product was purified by silica gel chromatography (ethyl acetate:hexane $=3: 1)$ to afford $3(7.8 \mathrm{~g}$, 93\%).

${ }^{1} \mathrm{H}$ NMR (300 MHz, $\mathrm{CDCl}_{3}$ ) $\delta 3.71$ (br m, 2H), 3.62-3.47 (m, 10H), 3.07 (br m, 4H), 
$1.71(\mathrm{~m}, 4 \mathrm{H}), 1.42(\mathrm{~s}, 18 \mathrm{H}) ;{ }^{13} \mathrm{C}$ NMR $\left(75 \mathrm{MHz}, \mathrm{CDCl}_{3}\right) \delta 168.73,165.46,165.12$, 156.29, 156.08, 79.40, 78.98, 72.54, 69.58, 69.38, 61.70, 44.14, 43.68, 41.17, 40.84, $38.38,37.76,36.95,28.52,28.25,28.00,27.88$; MS (ESI-TOF) calcd for $\mathrm{C}_{23} \mathrm{H}_{42} \mathrm{ClN}_{7} \mathrm{O}_{6}$ 547.29 , found $548.31(\mathrm{M}+\mathrm{H})^{+}$.

Intermediate 4. A solution of 3 (2.5 g, $4.6 \mathrm{mmol})$, TBDPS-Cl $(1.4 \mathrm{~mL}, 5.3 \mathrm{mmol})$, imidazole (250 mg, $3.7 \mathrm{mmol})$, and DIPEA $(0.90 \mathrm{~mL}, 5.2 \mathrm{~mL})$ in THF $(50 \mathrm{~mL})$ was stirred for $4 \mathrm{~h}$ at room temperature and the solvent was then removed by reducedpressure evaporation. The residue was dissolved in dichloromethane, washed with brine, dried over $\mathrm{MgSO}_{4}$ and evaporated under vacuum. The crude compound was purified by silica gel chromatography (ethyl acetate:hexane $=1: 1)$ to give $4(3.4 \mathrm{~g}, 94 \%)$ as a white solid.

${ }^{1} \mathrm{H}$ NMR $\left(300 \mathrm{MHz}, \mathrm{CDCl}_{3}\right) \delta 7.67(\mathrm{~m}, 4 \mathrm{H}), 7.40(\mathrm{~m}, 6 \mathrm{H}), 3.79(\mathrm{~m}, 2 \mathrm{H}), 3.62-3.46(\mathrm{~m}$, 10H), 3.07 (br m, 4H), 1.73 (m, 4H), 1.44 (s, 9H), 1.42 (s, 9H), 1.05 (s, 9H); ${ }^{13} \mathrm{C}$ NMR $\left(75 \mathrm{MHz}, \mathrm{CDCl}_{3}\right) \delta 168.93,165.50,165.26,156.31,156.02,135.68,133.62,129.81$, $127.80,79.34,78.98,72.52,72.34,69.84,69.52,63.50,43.85,43.51,41.00,37.55$, 36.90, 28.56, 27.96, 27.79, 26.92, 26.68, 19.29; MS (MALDI-TOF) calcd for $\mathrm{C}_{39} \mathrm{H}_{60} \mathrm{ClN}_{7} \mathrm{O}_{6} \mathrm{Si} 785.41$, found $786.44(\mathrm{M}+\mathrm{H})^{+}$.

Intermediate 5. Intermediate $3(2.9 \mathrm{~g}, 5.3 \mathrm{mmol})$ was dissolved in THF (50 mL) and 4aminomethyl piperidine $(2.0 \mathrm{~mL}, 16.6 \mathrm{mmol})$ was added. The solution was stirred for $8 \mathrm{~h}$ at room temperature and then evaporated under vacuum. The residue was dissolved in dichloromethane, washed with brine, dried over $\mathrm{MgSO}_{4}$, and evaporated under vacuum. The product was purified by silica gel chromatography (dichloromethane:methanol $=7: 1$ with $\left.1 \% \mathrm{NH}_{4} \mathrm{OH}\right)$ to give $5(3.2 \mathrm{~g}, 97 \%)$ as a white solid.

${ }^{1} \mathrm{H}$ NMR (300 MHz, $\left.\mathrm{CDCl}_{3}\right) \delta 4.69$ (br, 2H), 3.69 (t, $\left.J=4.5 \mathrm{~Hz}, 2 \mathrm{H}\right), 3.58-3.55$ (m, 10H), $3.02($ br s, 4H), $2.75(\mathrm{t}, J=12.2,2 \mathrm{H}) 2.57(\mathrm{~d}, J=6.3 \mathrm{~Hz}, 2 \mathrm{H}), 1.75-1.65(\mathrm{~m}, 6 \mathrm{H})$, 1.54 (br, 1H), 1.40 (s, 18H), 1.09 (m, 2H); $\left.{ }^{13} \mathrm{C} \mathrm{NMR} \mathrm{(75} \mathrm{MHz,} \mathrm{CDCl}_{3}\right) \delta 165.96,165.46$, 164.58, 155.99, 78.83, 72.37, 69.97, 61.34, 47.71, 43.16, 42.11, 40.47, 39.44, 38.35, 37.03, 29.67, 28.44, 27.67; MS (MALDI-TOF) calcd for $\mathrm{C}_{29} \mathrm{H}_{55} \mathrm{~N}_{9} \mathrm{O}_{6} 625.43$, found $626.59(\mathrm{M}+\mathrm{H})^{+}$.

Intermediate 6. Intermediate 4 ( $3.0 \mathrm{~g}, 3.84 \mathrm{mmol})$ was dissolved in THF (50 $\mathrm{mL})$ and 4-aminomethyl piperidine $(1.4 \mathrm{~mL}, 11.6 \mathrm{mmol})$ was added. The solution was stirred for $8 \mathrm{~h}$ at room temperature and then evaporated under vacuum. The residue was 
dissolved in dichloromethane, washed with brine, dried over $\mathrm{MgSO}_{4}$, and evaporated under vacuum. The product was purified by silica gel chromatography (dichloromethane:methanol $=7: 1$ with $\left.1 \% \mathrm{NH}_{4} \mathrm{OH}\right)$ to give $6(3.1 \mathrm{~g}, 93 \%)$ as a white solid.

${ }^{1} \mathrm{H}$ NMR (500 MHz, $\left.\mathrm{CDCl}_{3}\right) \delta 7.68(\mathrm{~m}, 4 \mathrm{H}), 7.39$ (m, 6H), 4.73 (br, 2H), 3.79 (t, J=5.3 $\mathrm{Hz}, 2 \mathrm{H}), 3.60-3.56(\mathrm{~m}, 10 \mathrm{H}), 3.04$ (br s, 4H), 2.77 (t, $J=11.3,2 \mathrm{H}) 2.60$ (d, J=6.5 Hz, 2H), 1.76-1.69 (m, 6H), $1.55(\mathrm{br}, 1 \mathrm{H}), 1.42(\mathrm{~s}, 18 \mathrm{H}), 1.11(\mathrm{~m}, 2 \mathrm{H}), 1.04(\mathrm{~s}, 9 \mathrm{H}) ;{ }^{13} \mathrm{C}$ NMR $\left(125 \mathrm{MHz}, \mathrm{CDCl}_{3}\right) \delta 166.12,165.77,164.86,156.13,135.69,133.74,129.72$, $127.75,79.05,72.35,70.26,63.50,47.97,43.32,42.14,40.73,39.74,37.28,36.96$, 29.85, 28.61, 27.66, 27.04, 26.92, 26.79, 19.28; MS (MALDI-TOF) calcd for $\mathrm{C}_{45} \mathrm{H}_{73} \mathrm{~N}_{9} \mathrm{O}_{6} \mathrm{Si} 863.55$, found $864.54(\mathrm{M}+\mathrm{H})^{+}$.

Intermediate 7. Cyanuric chloride (404 mg, $2.19 \mathrm{mmol}$ ) was added to an ice-bath cooled solution of 6 (1.893 g, $2.19 \mathrm{mmol})$ and DIPEA (1.4 mL, $8.0 \mathrm{mmol})$ in THF (50 $\mathrm{mL})$. The solution was stirred for $4 \mathrm{~h}$ at $0{ }^{\circ} \mathrm{C}$ before a THF solution $(20 \mathrm{~mL})$ of 5 $(1.403 \mathrm{~g}, 2.24 \mathrm{mmol})$ was added. The solution was stirred for $24 \mathrm{~h}$ at room temperature. After the addition of 4-aminomethyl piperidine $(3.0 \mathrm{~mL}, 25.0 \mathrm{mmol})$, the solution was stirred for an additional $24 \mathrm{~h}$ at room temperature and evaporated under vacuum. The residue was dissolved in dichloromethane, washed with brine, dried over $\mathrm{MgSO}_{4}$, and evaporated under vacuum. The crude product was purified by silica gel chromatography (dichloromethane:methanol = 7:1 with $\left.1 \% \mathrm{NH}_{4} \mathrm{OH}\right)$ to give $7(3.4 \mathrm{~g}$, $92 \%$ )

${ }^{1} \mathrm{H}$ NMR (300 MHz, $\left.\mathrm{CDCl}_{3}\right) \delta 7.67(\mathrm{~m}, 4 \mathrm{H}), 7.38(\mathrm{~m}, 6 \mathrm{H}), 4.72(\mathrm{br}, 6 \mathrm{H}), 3.79(\mathrm{t}, J=5.1$ $\mathrm{Hz}, 2 \mathrm{H}), 3.73(\mathrm{t}, J=4.4 \mathrm{~Hz}, 2 \mathrm{H}), 3.59-3.55(\mathrm{~m}, 20 \mathrm{H}), 3.28(\mathrm{br}, 4 \mathrm{H}), 3.05$ (br, 8H), 2.78-2.69 (br m, 8H), 1.77-1.70 (br m, 17H), 1.41 (s, 36H), 1.17 (m, 6H), 1.04 (s, 9H); ${ }^{13} \mathrm{C} \mathrm{NMR}\left(75 \mathrm{MHz}, \mathrm{CDCl}_{3}\right) \delta 166.03,165.78,165.62,164.86,164.70,156.15,135.72$, $133.77,129.75,127.78,79.08,72.37,70.29,70.15,63.51,61.76,47.50,46.28,46.19$, $43.33,43.26,42.43,40.75,38.90,37.27,30.03,29.83,28.63,27.83,26.95,19.31$; MS (MALDI-TOF) calcd for $\mathrm{C}_{83} \mathrm{H}_{139} \mathrm{~N}_{23} \mathrm{O}_{12} \mathrm{Si} 1678.07$, found $1679.27(\mathrm{M}+\mathrm{H})^{+}$.

Intermediate 8. Cyanuric chloride (170 $\mathrm{mg}, 0.922 \mathrm{mmol}$ ) was added to a solution of 7 $(3.139 \mathrm{~g}, 1.87 \mathrm{mmol})$ and DIPEA $(0.6 \mathrm{~mL}, 3.4 \mathrm{mmol})$ in THF $(80 \mathrm{~mL})$. The solution was stirred for $48 \mathrm{~h}$ at room temperature. After the addition of 4-aminomethyl piperidine $(1.5 \mathrm{~mL}, 12.5 \mathrm{mmol})$, the solution was stirred for an additional $24 \mathrm{~h}$, and then evaporated under vacuum. The residue was dissolved in dichloromethane, washed with brine, dried over $\mathrm{MgSO}_{4}$, and evaporated under vacuum. The product was purified by 
silica gel chromatography (dichloromethane:methanol $=7: 1$ with $1 \% \mathrm{NH}_{4} \mathrm{OH}$ ) to give 8 $(2.85 \mathrm{~g}, 87 \%)$ as a white solid.

${ }^{1} \mathrm{H}$ NMR (500 MHz, $\left.\mathrm{CDCl}_{3}\right) \delta 7.67(\mathrm{~m}, 8 \mathrm{H}), 7.37$ (m, 12H), 4.70 (br, 14H), 3.79 (t, $J=$ $5.3 \mathrm{~Hz}, 4 \mathrm{H}), 3.72$ (br , 4H), 3.58-3.55 (m, 40H), 3.26 (br , 12H), 3.05 (br, 16H), 2.75 (br , 16H), 1.76-1.69 (br m, 37H), 1.41 (s, 72H), 1.16 (br, 14H), 1.03 (s, 18H); ${ }^{13} \mathrm{C} \mathrm{NMR}$ $\left(125 \mathrm{MHz}, \mathrm{CDCl}_{3}\right) \delta 165.83,164.80,156.14,135.69,133.74,129.73,127.76,79.05$, $72.42,72.35,70.27,70.13,63.49,61.66,46.14,43.31,43.24,42.35,40.73,40.64,37.20$, 36.97, 30.01, 29.75, 28.62, 27.80, 26.93, 19.29; MS (MALDI-TOF) calcd for $\mathrm{C}_{175} \mathrm{H}_{289} \mathrm{~N}_{51} \mathrm{O}_{24} \mathrm{Si}_{2} 3545.25$, found $3546.19(\mathrm{M}+\mathrm{H})^{+}$.

Intermediate 9. Cyanuric chloride $(62 \mathrm{mg}, 0.336 \mathrm{mmol})$ was added to an ice-bath cooled solution of 8 ( $800 \mathrm{mg}, 0.226 \mathrm{mmol})$ and DIPEA $(174 \mu \mathrm{L}, 1.0 \mathrm{mmol})$ in THF (20 $\mathrm{mL}$ ). The reaction solution was stirred for $5 \mathrm{~h}$ at $0{ }^{\circ} \mathrm{C}$ and then evaporated under vacuum. The residue was dissolved in dichloromethane, washed with brine, dried over $\mathrm{MgSO}_{4}$, and evaporated under vacuum. The crude product was purified by silica gel chromatography (ethyl acetate to dichloromethane:methanol $=8: 1)$ to give $9(690 \mathrm{mg}$, $83 \%)$ as a white solid.

${ }^{1} \mathrm{H}$ NMR (500 MHz, $\mathrm{CDCl}_{3}$ ) $\delta 7.67$ (m, 8H), 7.36 (m, 12H), 4.68 (br, 14H), 3.78 (t, $J=$ $5.0 \mathrm{~Hz}, 4 \mathrm{H}), 3.70$ (br , 4H), 3.57-3.54 (m, 40H), 3.24 (br , 14H), 3.03 (br, 16H), 2.73 (br, 14H), 1.72-1.68 (br, 37H), 1.39 (s, 72H), 1.14 (br, 14H), $1.02(\mathrm{~s}, 18 \mathrm{H}) ;{ }^{13} \mathrm{C} \mathrm{NMR}$ $\left(125 \mathrm{MHz}, \mathrm{CDCl}_{3}\right) \delta 170.83,166.02,164.73,156.07,135.61,133.65,129.66,127.69$, 78.96, 72.38, 72.26, 70.18, 63.42, 61.59, 46.78, 46.17, 43.20, 42.22, 40.66, 40.55, 37.18, 36.88, 29.95, 29.59, 28.55, 27.72, 26.86, 19.21; MS (MALDI-TOF) calcd for $\mathrm{C}_{178} \mathrm{H}_{288} \mathrm{Cl}_{2} \mathrm{~N}_{54} \mathrm{O}_{24} \mathrm{Si}_{2} 3692.19$, found $3693.14(\mathrm{M}+\mathrm{H})^{+}$.

Dendrimer 1. A solution of piperazine $(3.2 \mathrm{mg}, 0.0371 \mathrm{mmol})$ and DIPEA (40 $\mu \mathrm{L}$, $0.232 \mathrm{mmol})$ in methanol $(1 \mathrm{~mL})$ was added dropwise to an ice-bath cooled solution of 9 (300 mg, $0.0812 \mathrm{mmol})$ in THF $(6 \mathrm{~mL})$. The solution was warmed to room temperature, stirred for $48 \mathrm{hr}$, and then evaporated under vacuum. The residue was dissolved in dichloromethane, washed with brine, dried over $\mathrm{MgSO}_{4}$, and evaporated under vacuum. The crude product was purified by silica gel chromatography (ethyl acetate to dichloromethane:methanol $=8: 1)$ to give $\mathbf{1}(233 \mathrm{mg}, 85 \%)$ as a white solid. ${ }^{1} \mathrm{H}$ NMR (500 MHz, $\left.\mathrm{CDCl}_{3}\right) \delta 7.66(\mathrm{~m}, 16 \mathrm{H}), 7.33$ (m, 24H), 4.69 (br, 28H), 3.84 (br, $8 \mathrm{H}), 3.78(\mathrm{t}, J=5.3 \mathrm{~Hz}, 8 \mathrm{H}), 3.71$ (br , 8H), 3.58-3.55 (m, 80H), 3.25 (br , 28H), 3.04 (br, 32H), 2.74 (br , 28H), 1.73-1.68 (br , 74H), 1.40 (s, 144H), 1.15 (br, 28H), 1.03 (s, $36 \mathrm{H}) ;{ }^{13} \mathrm{C} \mathrm{NMR}\left(125 \mathrm{MHz}, \mathrm{CDCl}_{3}\right) \delta 165.80,164.78,164.67,156.10,135.65,133.69$, 
$129.69,127.73,78.99,72.41,72.30,70.22,70.15,63.45,61.64,46.23,43.22,42.28$, 40.69, 40.59, 37.18, 36.94, 29.99, 29.75, 28.59, 27.78, 26.89, 19.24; MS (MALDI-TOF) calcd for $\mathrm{C}_{360} \mathrm{H}_{584} \mathrm{Cl}_{2} \mathrm{~N}_{110} \mathrm{O}_{48} \mathrm{Si}_{4} 7398.51$, found $7399.18(\mathrm{M}+\mathrm{H})^{+}$.

Bolton-Hunter reagent linked to BOC-piperazine. 1-BOC-piperazine $(0.56 \mathrm{~g}, 3.0$ mmol) and DIPEA $(0.8 \mathrm{~mL}, 4.6 \mathrm{mmol})$ were added to a solution of 3-(4hydroxyphenyl)propionic acid $(0.50 \mathrm{~g}, 3.0 \mathrm{mmol})$ and PyBOP $(1.72 \mathrm{~g}, 3.3 \mathrm{mmol})$ in DMF $(10 \mathrm{~mL})$. The solution was stirred for $12 \mathrm{hr}$ at room temperature. The reaction mixture was poured into $50 \mathrm{~mL}$ of $0.5 \mathrm{M} \mathrm{KHSO}_{4}(\mathrm{aq})$ and extracted with ethyl acetate. The organic layer was washed with Sat. $\mathrm{NaHCO}_{3}$ (aq), dried over $\mathrm{MgSO}_{4}$, and then evaporated under vacuum. The crude product was purified by silica gel chromatography (ethyl acetate:hexane $=3: 1$ ) to afford a white hygroscopic solid (1.0 g, $99 \%)$.

${ }^{1} \mathrm{H}$ NMR (300 MHz, $\left.\mathrm{CDCl}_{3}\right) \delta 7.07$ (dd, $\left.J=6.5,2.0,2 \mathrm{H},\right), 6.76(\mathrm{dd}, J=6.5,2.3,2 \mathrm{H})$, $3.58(\mathrm{t}, J=5.3 \mathrm{~Hz}, 2 \mathrm{H}), 3.39-3.31(\mathrm{~m}, 6 \mathrm{H}), 2.90(\mathrm{t}, J=7.8 \mathrm{~Hz}, 2 \mathrm{H}), 2.60$ (t, $J=7.7 \mathrm{~Hz}$, 2H), $1.46(\mathrm{~s}, 9 \mathrm{H}) ;{ }^{13} \mathrm{C} \mathrm{NMR}\left(75 \mathrm{MHz}, \mathrm{CDCl}_{3}\right) \delta 171.75,155.24,154.67,131.67,129.42$, $115.50,80.67,45.47,43.08,41.53,35.31,30.77,28.36$; MS (ESI-TOF) calcd for $\mathrm{C}_{18} \mathrm{H}_{26} \mathrm{~N}_{2} \mathrm{O}_{4} 334.19$, found $335.19(\mathrm{M}+\mathrm{H})^{+}$.

Bolton-Hunter reagent linked to piperazine. Trifluoroacetic acid $(10 \mathrm{~mL})$ was added to an ice-bath cooled solution of the modified Bolton-Hunter reagent (1.0 g, $2.99 \mathrm{mmol})$ in dichloromethane $(10 \mathrm{~mL})$. The solution was warmed to room temperature and stirred for $4 \mathrm{hr}$. The solution was concentrated under vacuum to give a TFA salt.

${ }^{1} \mathrm{H}$ NMR (300 MHz, MeOH-d 4 ) $\delta 7.04$ (dd, $\left.J=6.6,2.1,2 \mathrm{H}\right), 6.72(\mathrm{dd}, J=6.5,2.0,2 \mathrm{H})$, $3.78(\mathrm{t}, J=5.0 \mathrm{~Hz}, 2 \mathrm{H}), 3.65(\mathrm{t}, J=5.0 \mathrm{~Hz}, 2 \mathrm{H}), 3.11(\mathrm{t}, J=5.1 \mathrm{~Hz}, 2 \mathrm{H}), 2.97(\mathrm{t}, J=5.0$ $\mathrm{Hz}, 2 \mathrm{H}), 2.82(\mathrm{t}, J=7.5 \mathrm{~Hz}, 2 \mathrm{H}), 2.66(\mathrm{t}, J=7.1 \mathrm{~Hz}, 2 \mathrm{H}) ;{ }^{13} \mathrm{C} \mathrm{NMR}(75 \mathrm{MHz}, \mathrm{MeOH}-$ $\left.\mathrm{d}_{4}\right) \delta 173.71,156.94,132.63,130.61,116.29,44.28,43.64,39.38,35.41,31.74$; MS (ESI-TOF) calcd for $\mathrm{C}_{13} \mathrm{H}_{18} \mathrm{~N}_{2} \mathrm{O}_{2} 234.14$, found $235.12(\mathrm{M}+\mathrm{H})^{+}$.

Dendrimer 10. A solution of the modified Bolton-Hunter reagent salt $(180 \mathrm{mg})$ in methanol $(2 \mathrm{~mL})$ was added to a solution of dendrimer $1(150 \mathrm{mg}, 0.020 \mathrm{mmol})$ and DIPEA $(0.4 \mathrm{~mL}, 2.3 \mathrm{mmol})$ in dichloromethane $(1 \mathrm{~mL})$. The solution was stirred for 7 days at room temperature and the solvent was then removed by reduced-pressure evaporation. The residue was dissolved in dichloromethane, washed with brine, dried over $\mathrm{MgSO}_{4}$ and evaporated under vacuum. The crude compound was purified by silica gel chromatography (dichloromethane:methanol = 10:1) to give $\mathbf{1 0}(155 \mathrm{mg}, 98 \%)$ 
as a white solid.

${ }^{1} \mathrm{H}$ NMR (500 MHz, $\mathrm{CDCl}_{3}+{\left.\mathrm{MeOH}-\mathrm{d}_{4}\right) \delta} 7.97$ (dd, $\left.J=7.8,1.3,16 \mathrm{H}\right), 7.68(\mathrm{~m}, 24 \mathrm{H})$, $7.32(\mathrm{~d}, J=8.0,4 \mathrm{H}), 7.04(\mathrm{~d}, J=7.5,4 \mathrm{H}), 4.98$ (br, 28H), 4.10-3.85 (m, 120H), 3.56 (br, 28H), 3.34 (br, 32H), 3.17 (t, $J=7.3 \mathrm{~Hz}, 4 \mathrm{H}), 3.07$ (br, 28H), 2.92 (br, 4H), 2.08-2.01 (br, 74H), $1.71(\mathrm{~s}, 144 \mathrm{H}), 1.46$ (br, 28H), $1.33(\mathrm{~s}, 36 \mathrm{H}) ;{ }^{13} \mathrm{C} \mathrm{NMR}(125 \mathrm{MHz}$, $\left.\mathrm{CDCl}_{3}+\mathrm{MeOH}_{-} \mathrm{d}_{4}\right) \delta 171.74,166.18,165.82,165.35,164.81,164.48,156.34,155.22$, $135.41,133.40,131.40,129.51,129.24,127.51,115.22,79.08,72.20,72.09,69.98$, $69.78,63.23,61.16,45.93,45.49,43.05,42.86,42.53,41.42,40.36,40.26,37.08,36.80$, $35.21,30.73,30.06,29.73,29.49,29.18,28.75,28.23,27.52,26.60,18.97$; MS (MALDI-TOF) calcd for $\mathrm{C}_{386} \mathrm{H}_{618} \mathrm{~N}_{114} \mathrm{O}_{52} \mathrm{Si}_{4} 7794.83$, found $7794.11(\mathrm{M}+\mathrm{H})^{+}$. 
+TOF MS: 3 MCA scans trom 11020413. Witt

$\mathrm{a}=3.55239114848213870 \mathrm{e}-004, \mathrm{t} 0=4.38015158811649600 \mathrm{e}+001$

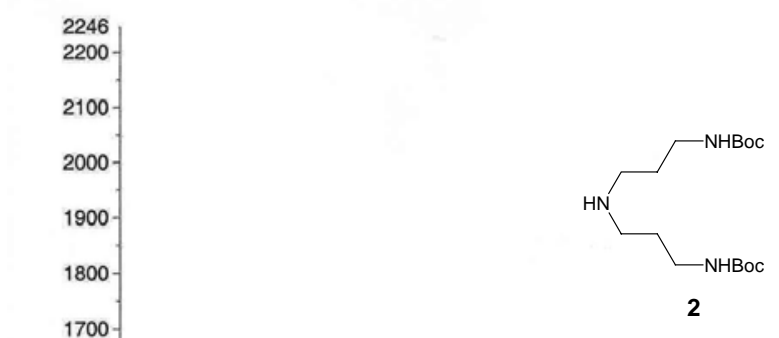

Max. 2246.0 coun

332.2725

$$
(\mathrm{M}+\mathrm{H})+
$$

120

140

160

180

200

300

320

340

360

380

401 
Int2

Pulse Sequence: s2pu

Solvent: CdC13
Aiblent temperature
nebrcury-300BB "mercury $300^{\prime \prime}$

Relax. delay $1.000 \mathrm{sec}$

Acc. time 1.955 sec

Weth $4506.5 \mathrm{~Hz}$
32 repetitions
osserve

DESERVE H1
DATA PROCESSIMG

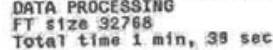
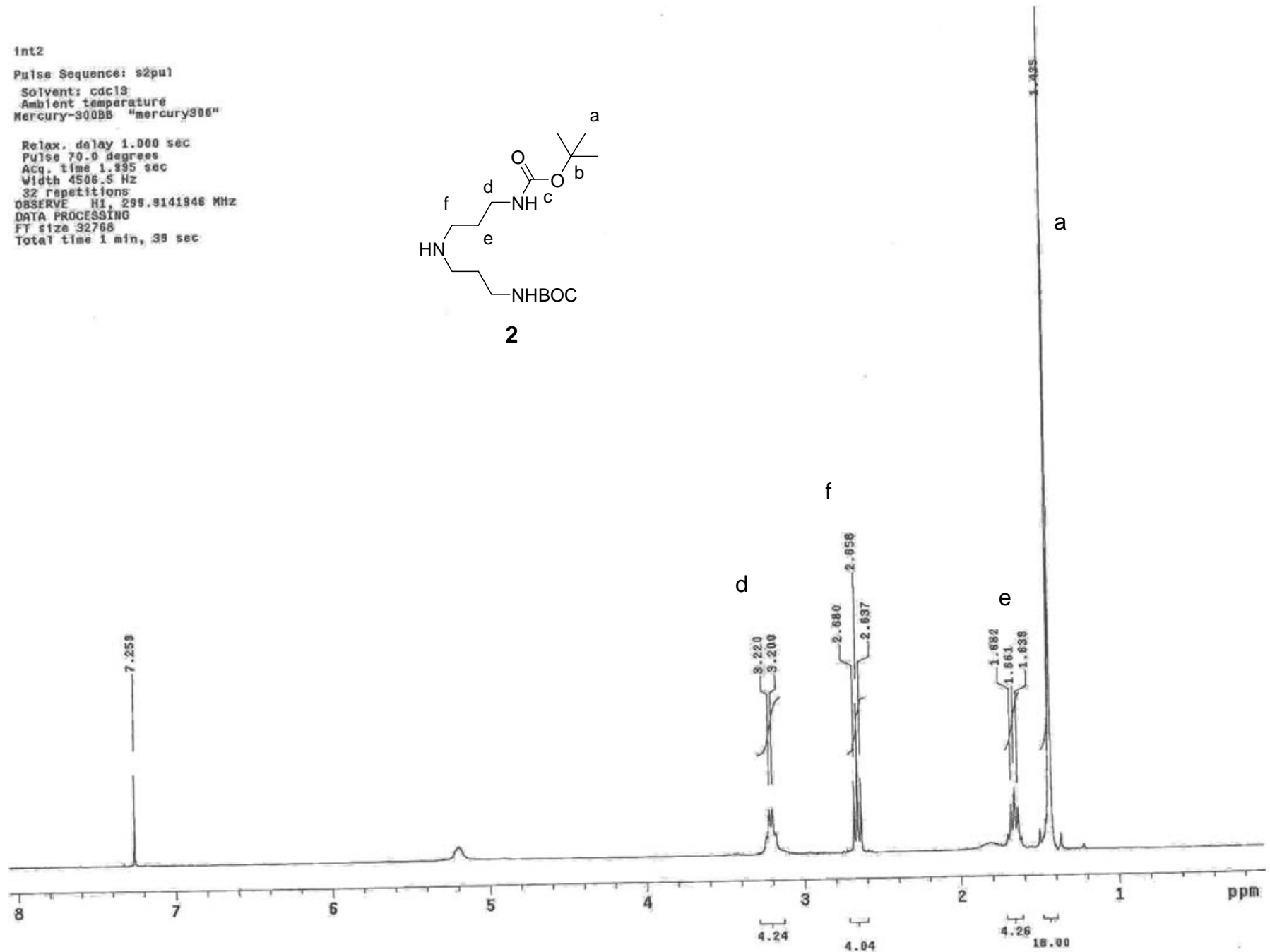
int2

Pulse Sequence: s2pul

Solvent: edc13
Ambient $t$ temperature

User: jditim arbon
File: int2carbon
INOVA-500 "nmrsun2"

Pulse 84.8 degrees
Acq. time $1.815 \mathrm{sec}$

Width $18761.7 \mathrm{~Hz}$

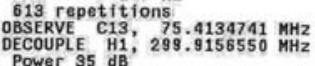

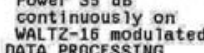

DATA PROCESSING
Iine broadening $1.0 \mathrm{~Hz}$

FT size 131072 .
Total time $31 \mathrm{~min}, 7 \mathrm{sec}$
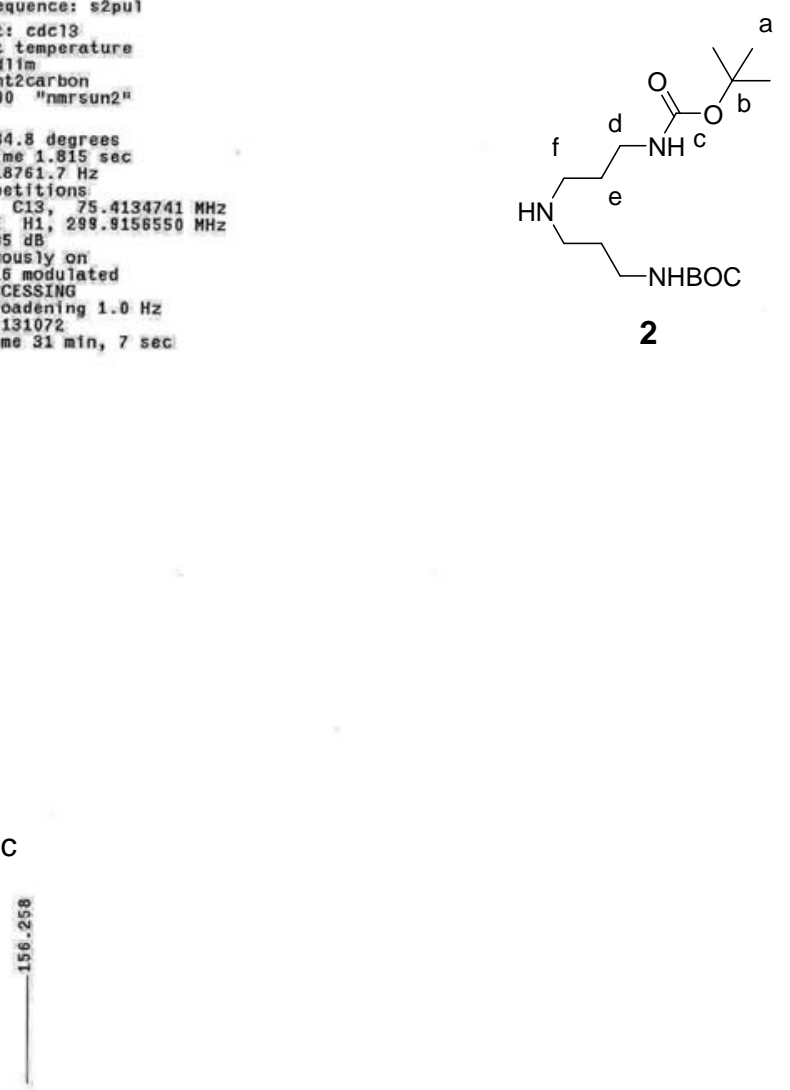

b

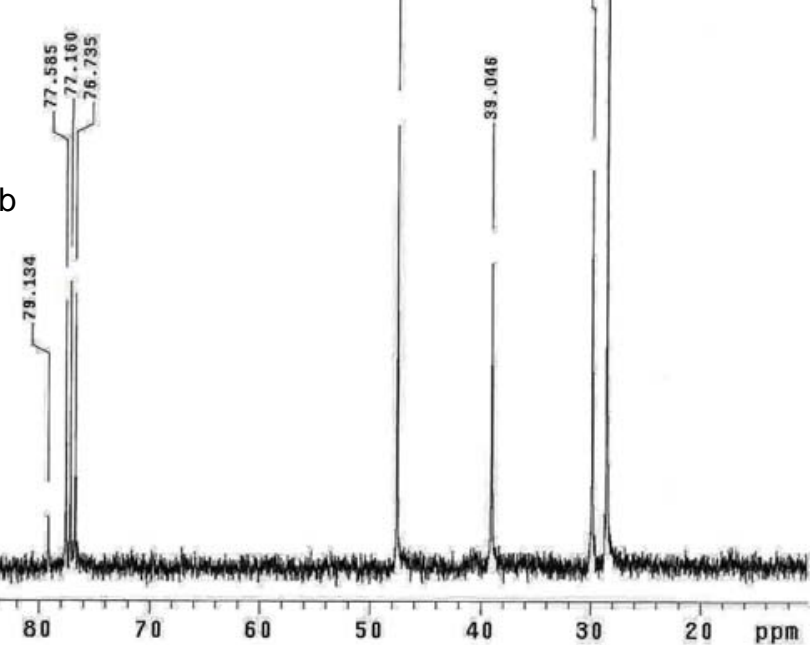




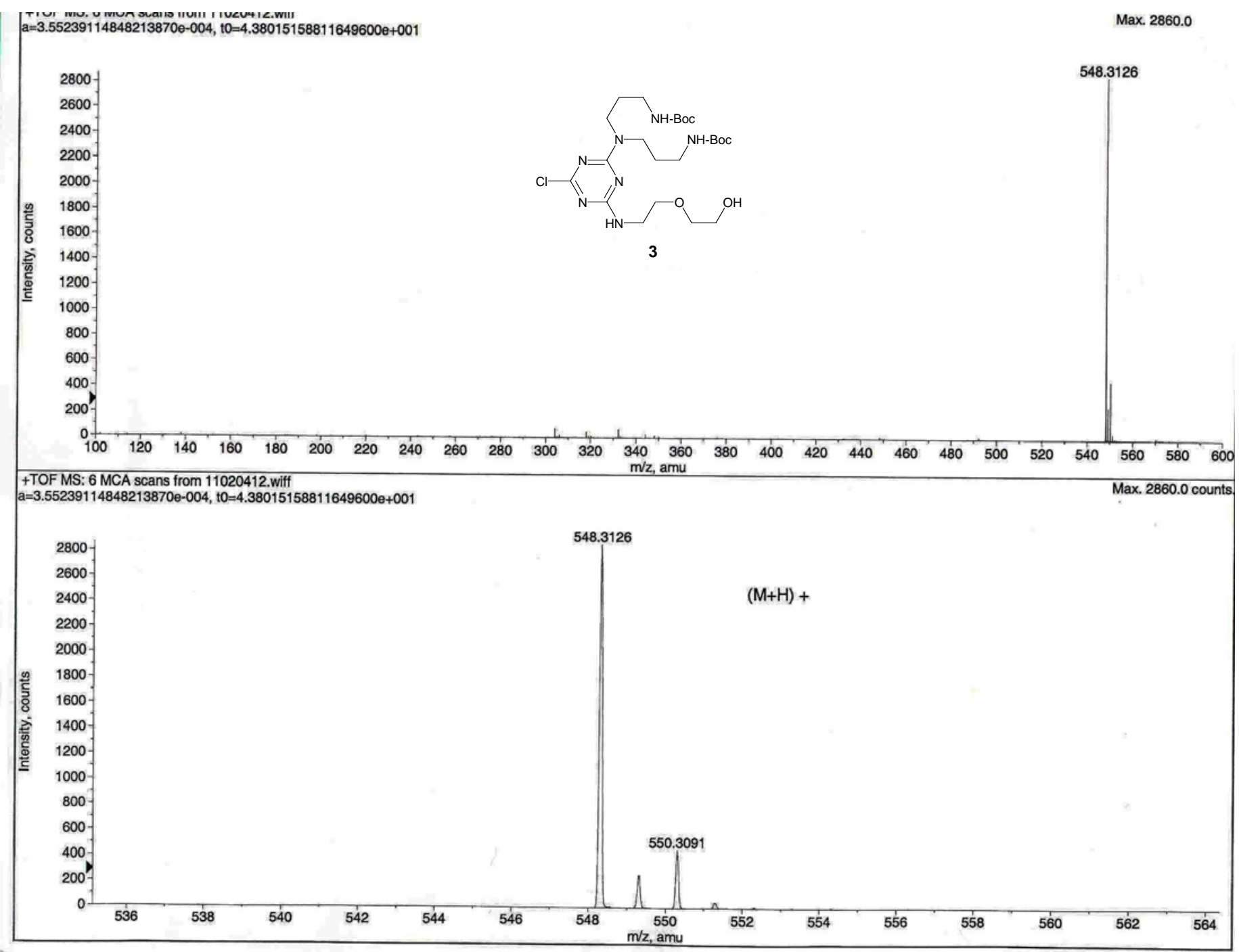




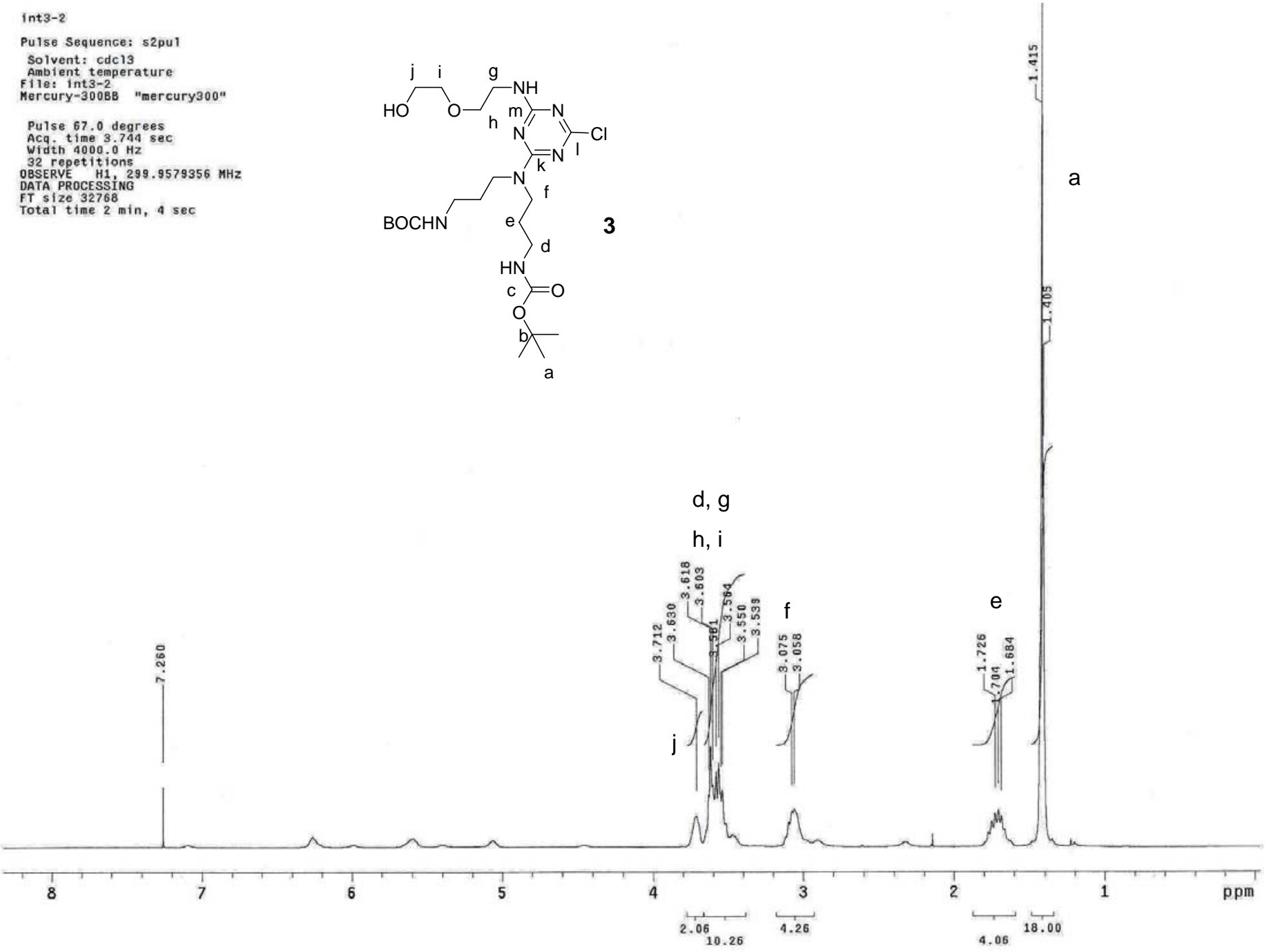


int3
Pulse Sequence: s2pui
Solvent: cdc13

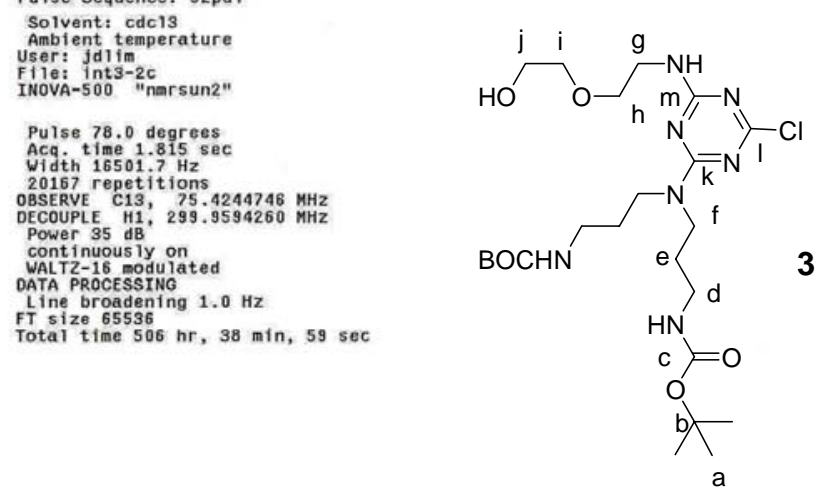

$\mathrm{k}, \mathrm{m} \quad \mathrm{c}$

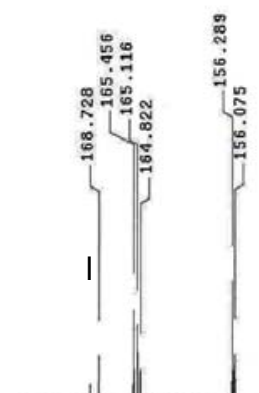

. 

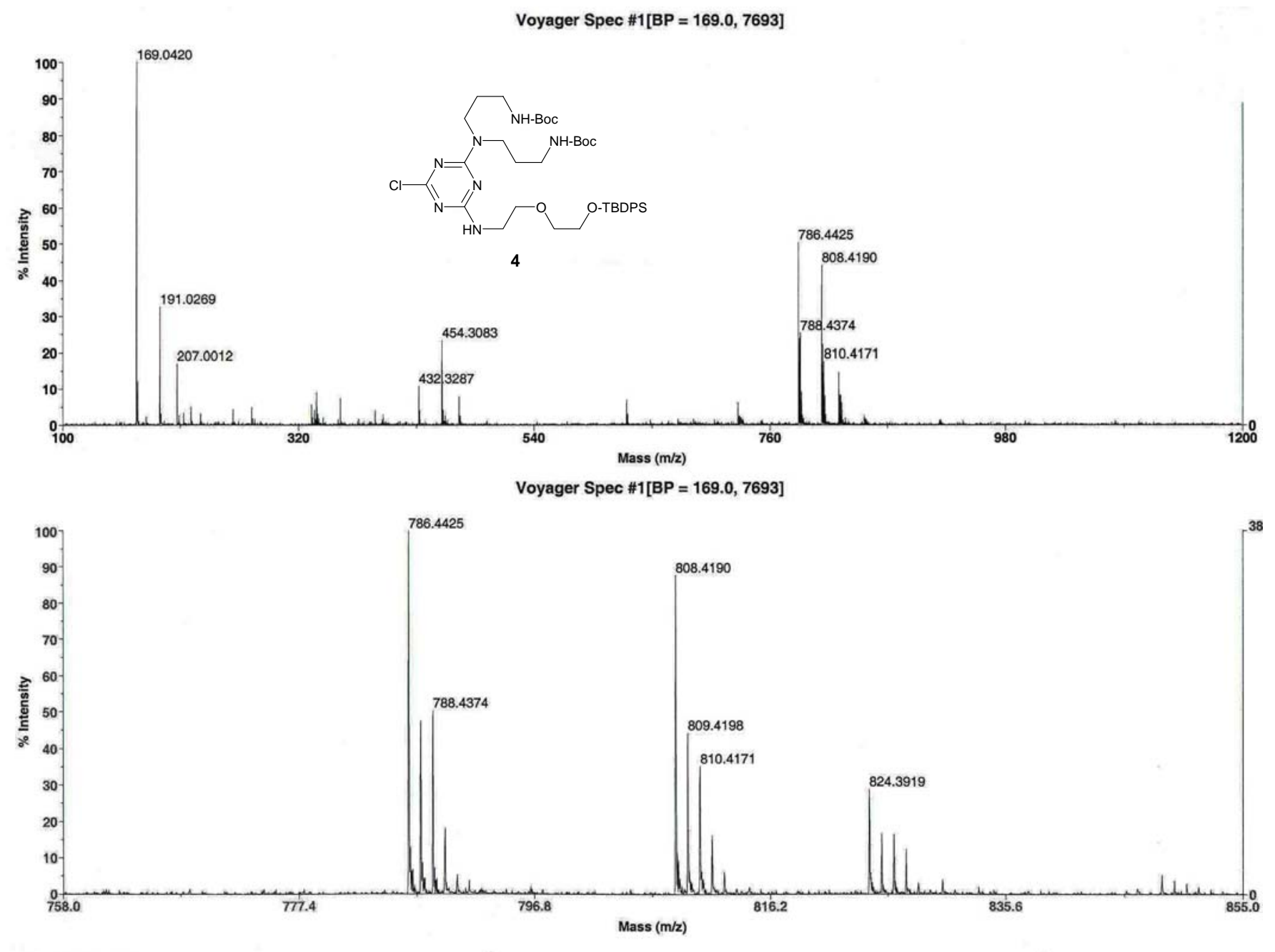

D:L.LI11220401_0002.dat

mber 22, 2004 
int

Pulse Sequence: s2pul

Solvent: $c d c 13$
Ambient temperatur

User: jdi1m
File: int41211H
INovA-500 "nmrsun2"

Re lax. delay $1.000 \mathrm{sec}$

pcise

Width $4506.5 \mathrm{~Hz}$

OBSRRY

DATA PROCESSING

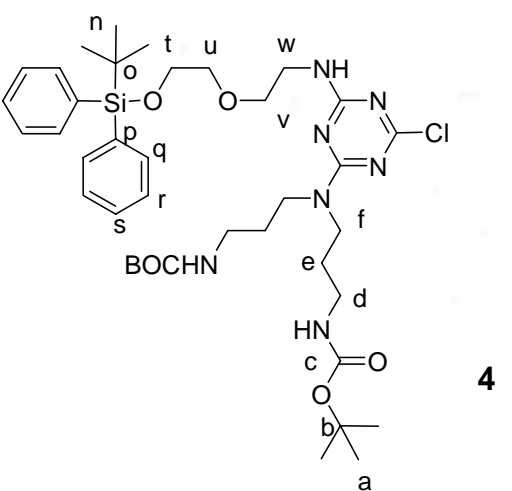

4

a
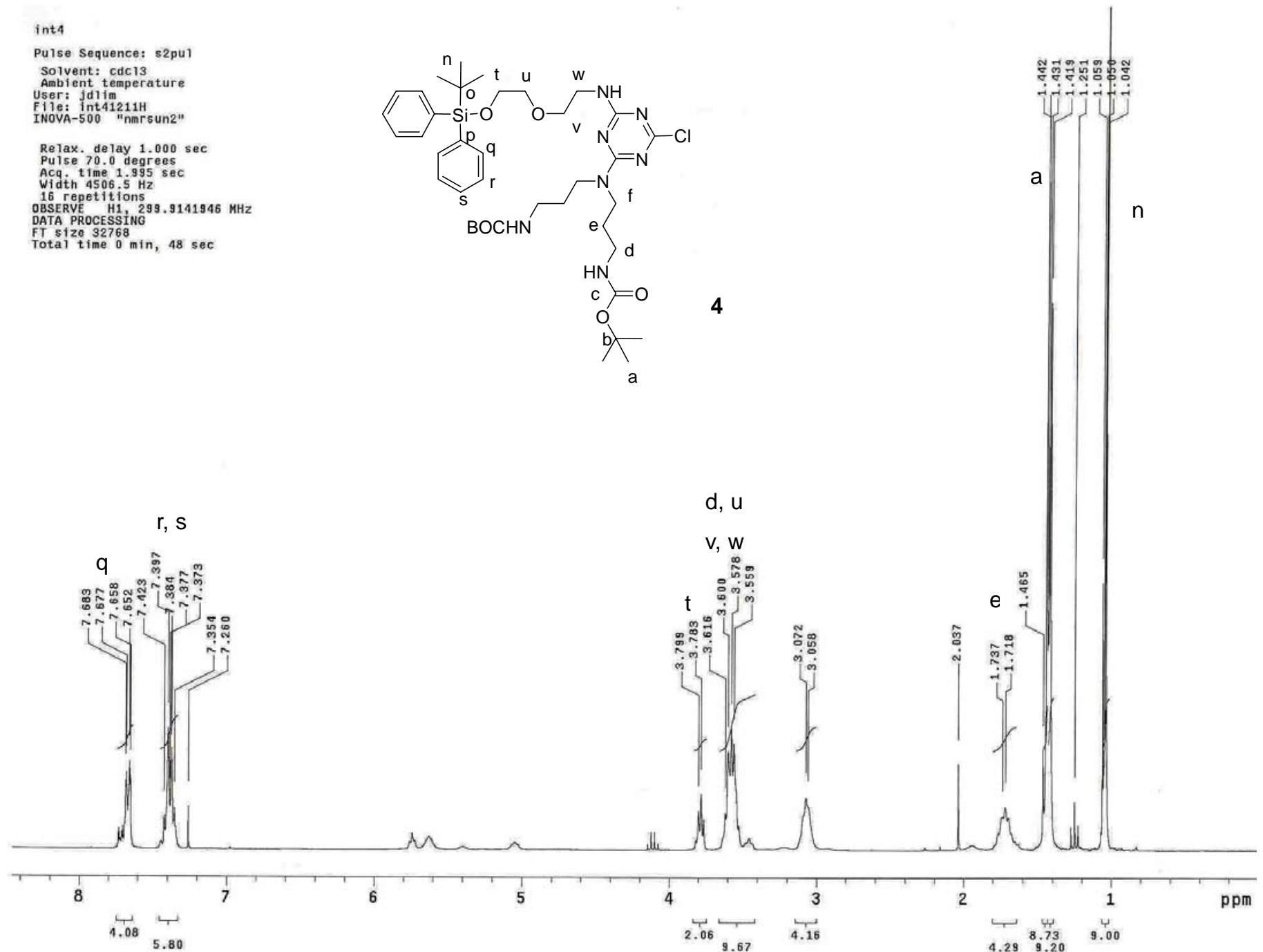

$2 . 0 6 \longdiv { 9 . 6 7 } \quad 4 . 1 6$

$8.73 \quad 9$ 


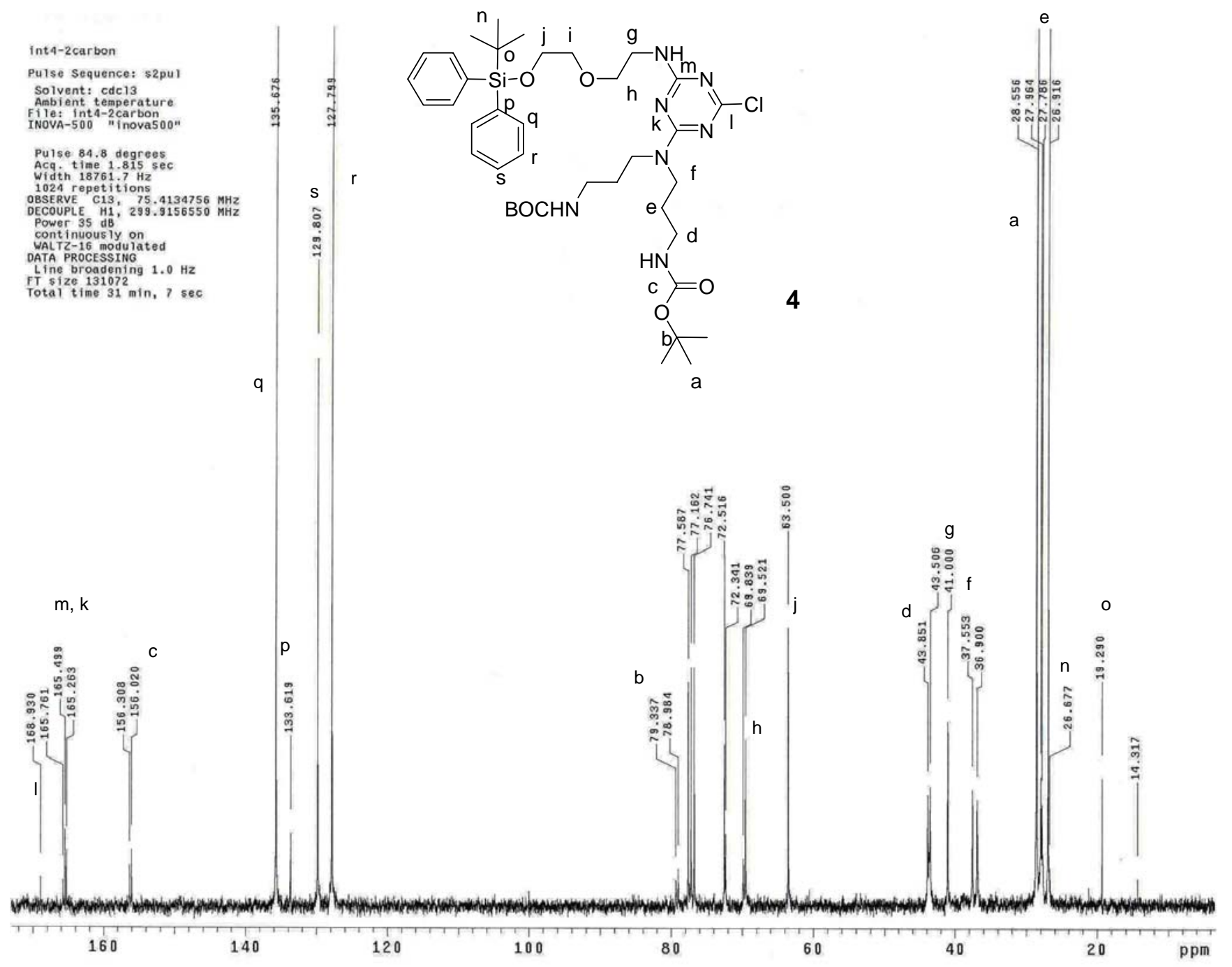


Voyager Spec \#1[BP = 626.6, 13627]
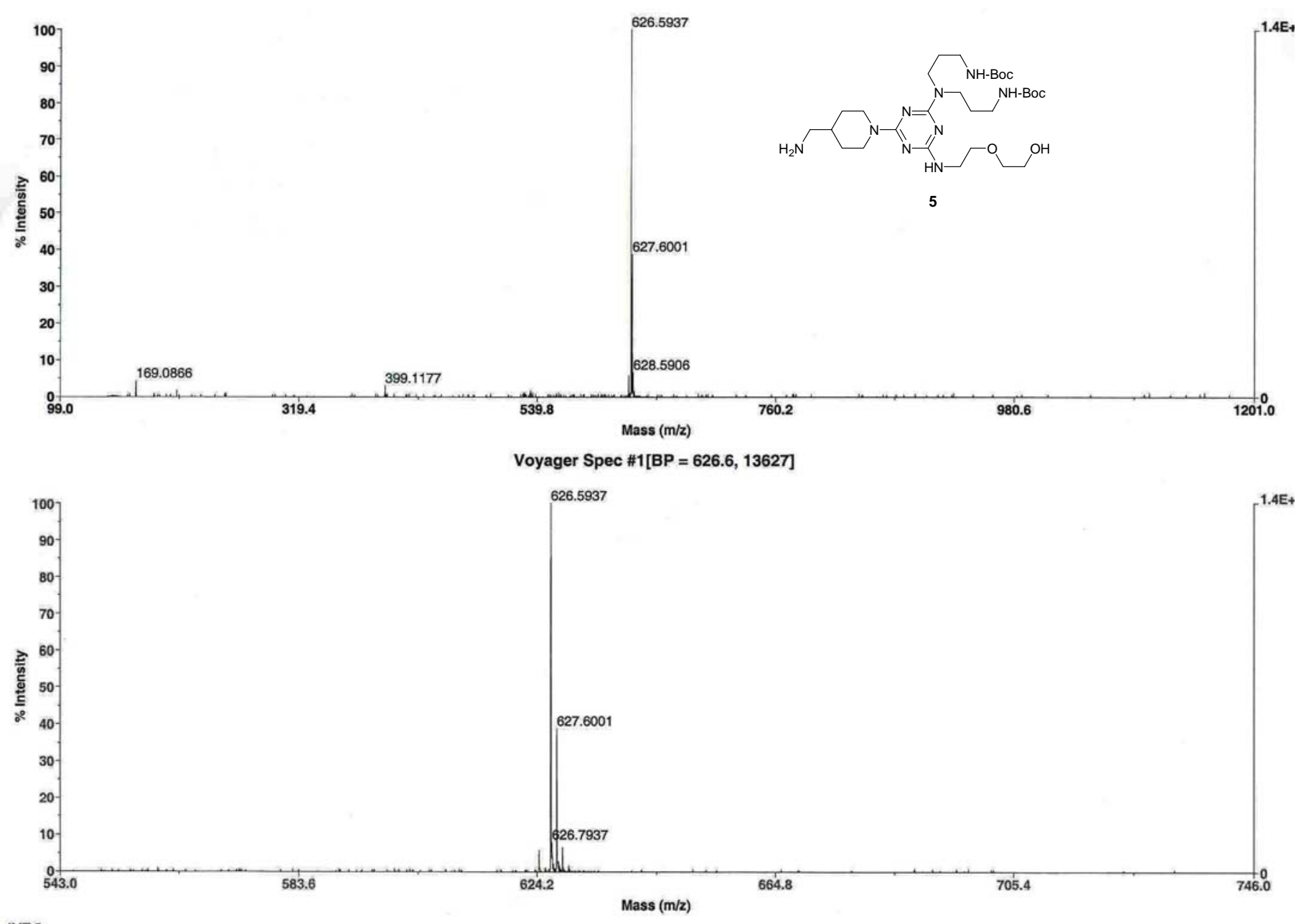

IMT 5 5
Di...I11230404_0001.dat

Acquired: 14:59:00, November 23, 2004 


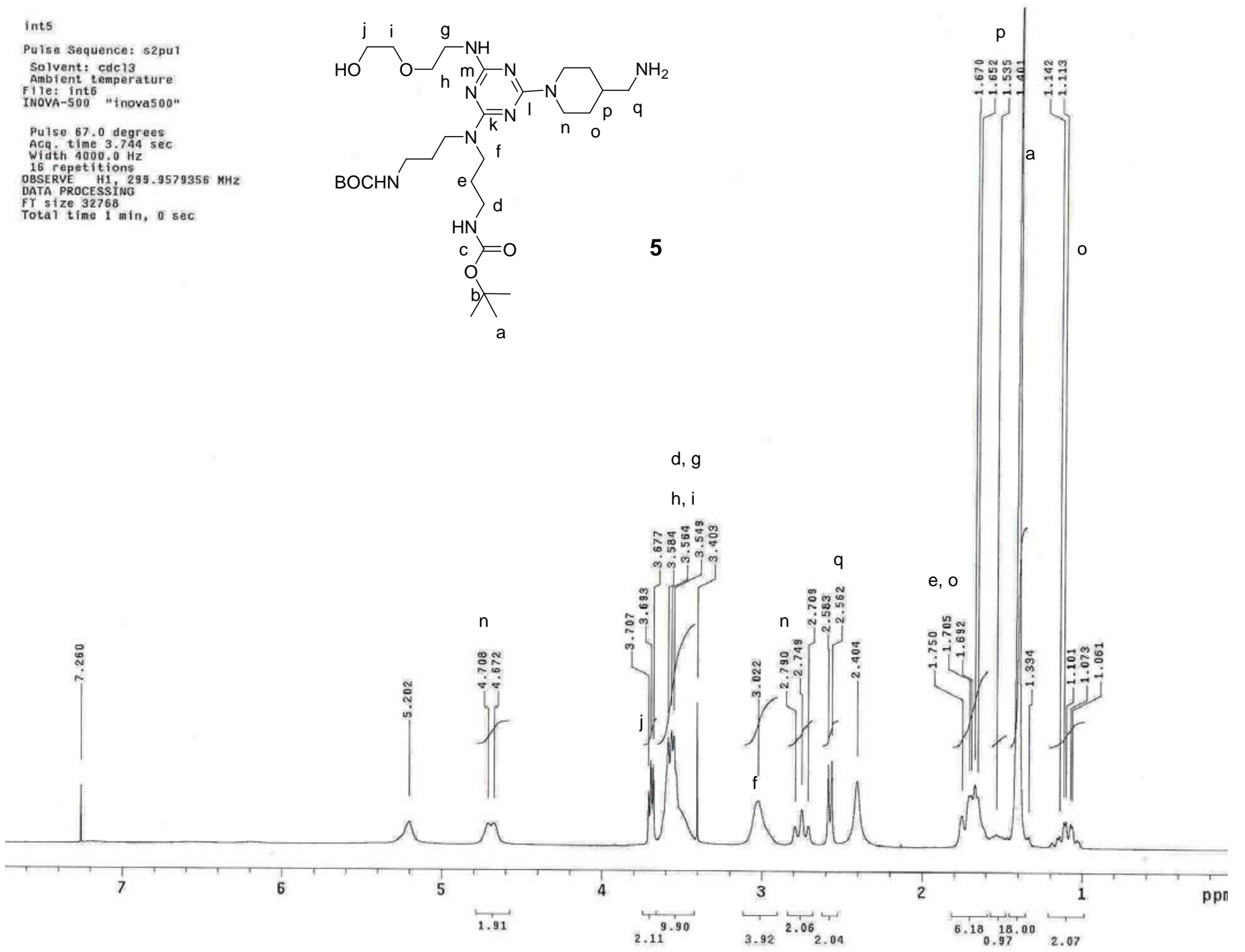


int6

Puise Sequence: s2pu

Solvent: : Cdc13

Ambient temperature
Mercury-300BB "mercurysoo"

Pulse 84.8 degrees
ACq. time $1.815 \mathrm{sec}$

Width $18761.7 \mathrm{~Hz}$

505 repetitions
OBSERE C13, 75.4134844 MHZ
DECOUPLE H1; 299.9156550 HHZ

Power 35 di
continuous $1 y$ on
walT

ATA PROCESSING

ine broadening 1.0

otal time $117 \mathrm{hr}, 20 \mathrm{~min}, 24 \mathrm{sec}$
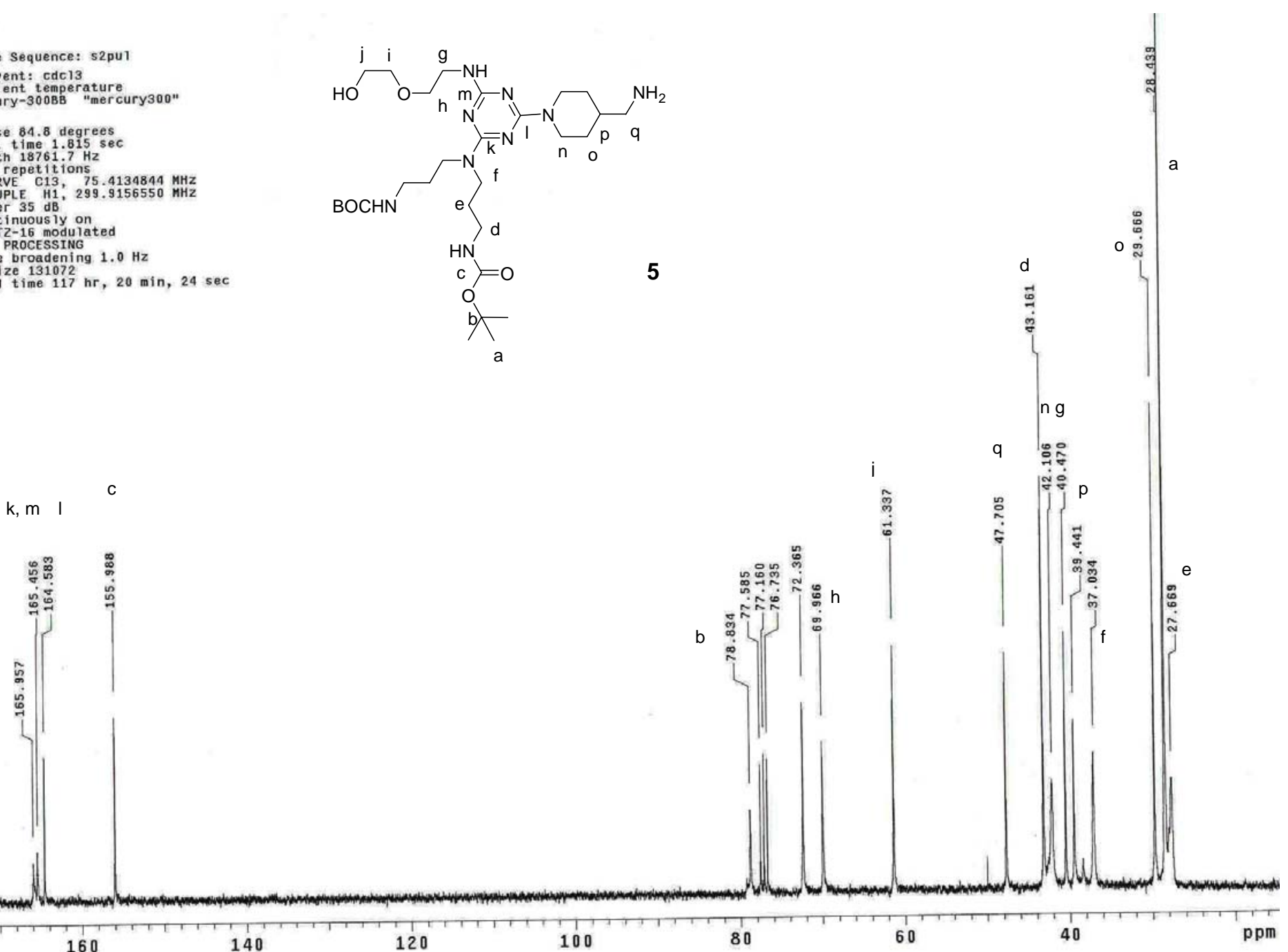

160 


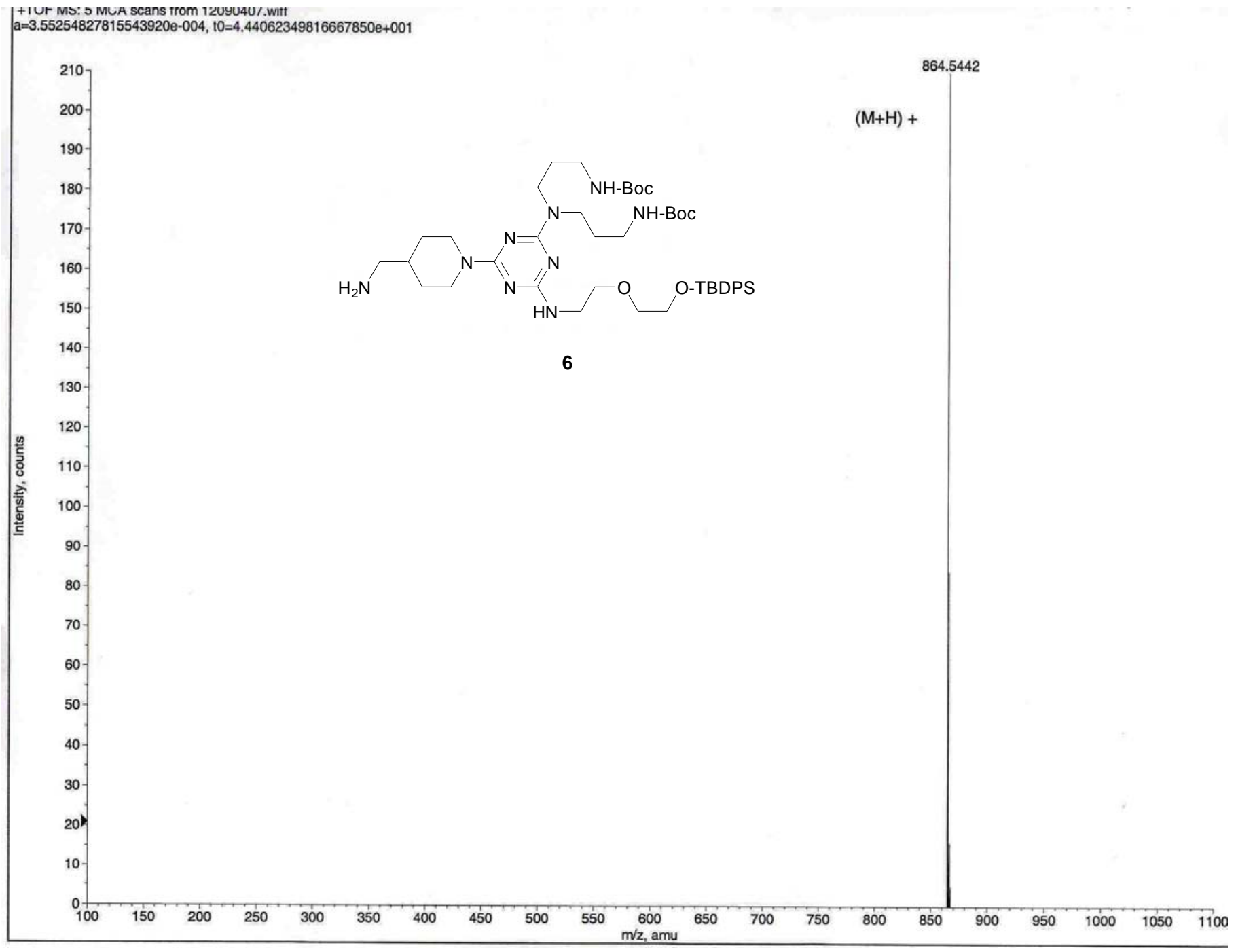


int5

Pulse Sequence: 52 pul

Solvent: cdc13
Ambient temperature

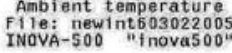

Pulse 46.7 tegrees
Acq. time $2.892 \mathrm{sec}$

Width $8000.0 \mathrm{~Hz}$

H1, 500.0267250 MHZ

ET size 65536
Total time $0 \mathrm{~min}, 23 \mathrm{sec}$
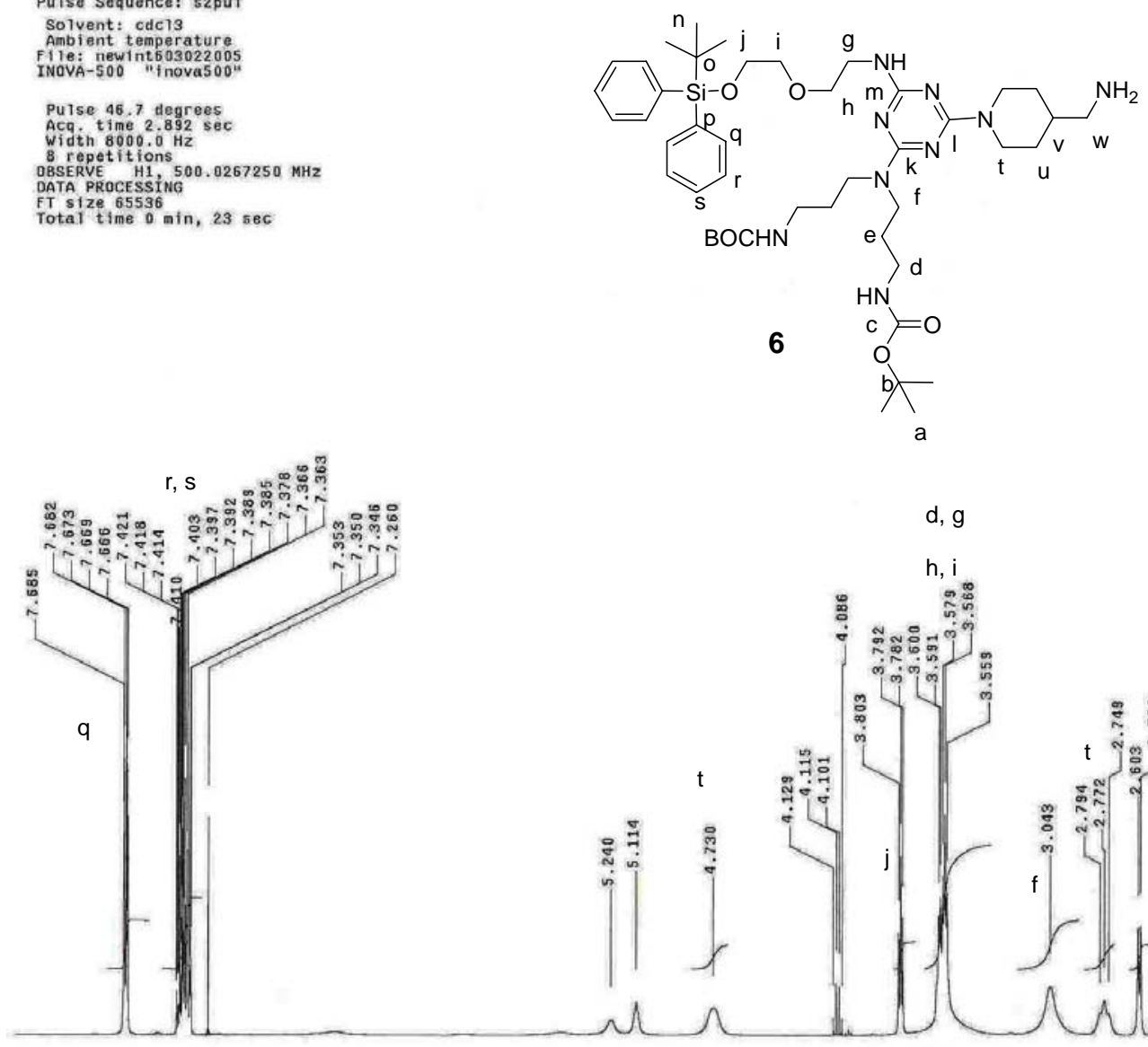

$\mathrm{u}$

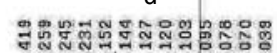

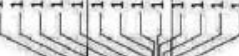

(n)

a

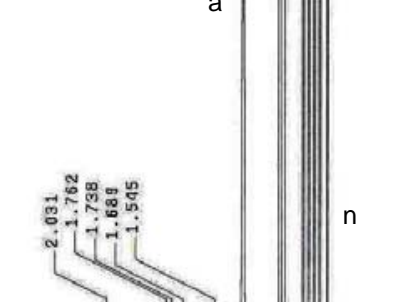

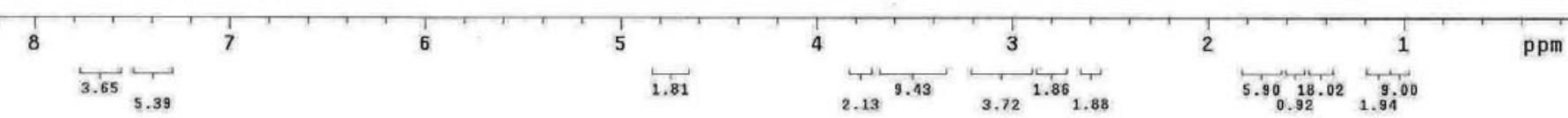


int?

Pulse Sequence: s2pul

Solvent: cdc1 13
Ambent temerature

Amb ent temperature
File: newinticarbon
INOVA-500 "inova500

Pulse 63.5 degrees

Acr. time 1.300 se

OBSERE TC13, 125.7318065 MH
OECOUPLE H1, 500.0282238 HH

Power $42 \mathrm{~dB}$ a
continuous $7 y$ on

WALT2-16 modulated

DATA PROCESSING $0.5 \mathrm{HZ}$

FT size 65536 .

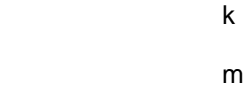

m

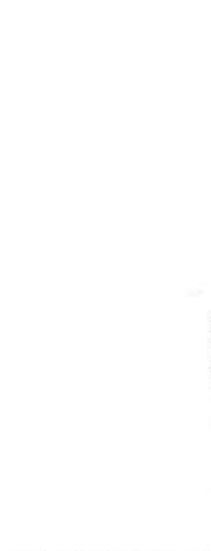

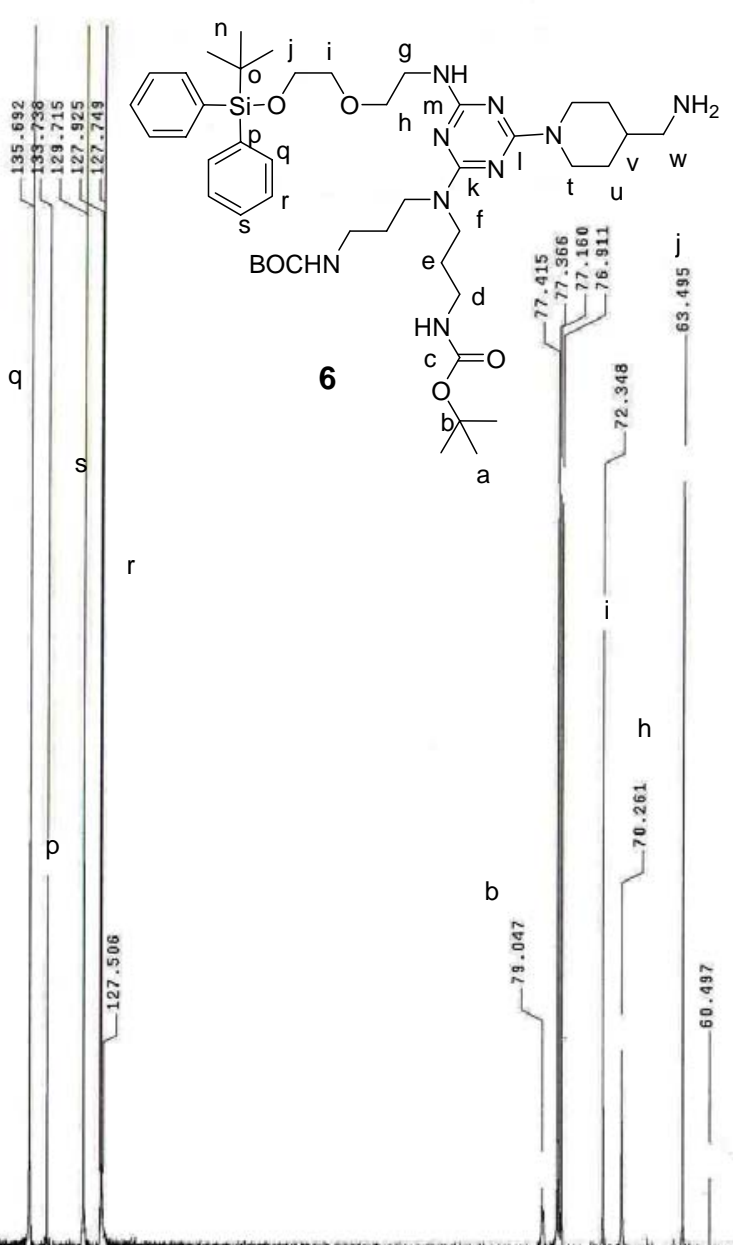

a e

范궁ำ

สุกิสกิสัก
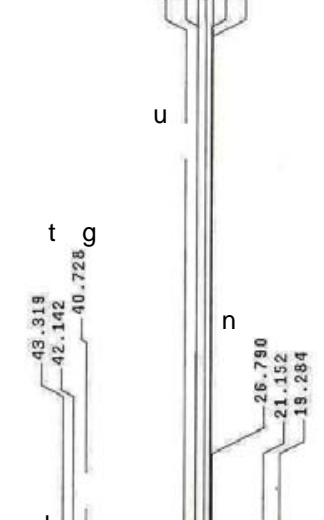

d
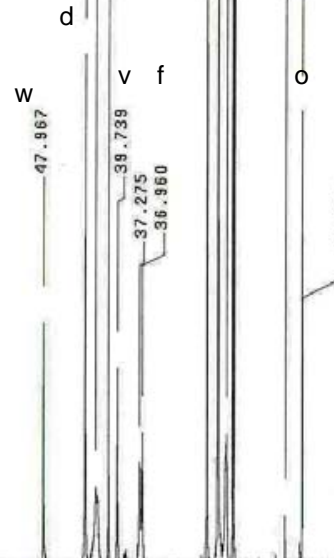

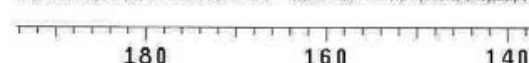



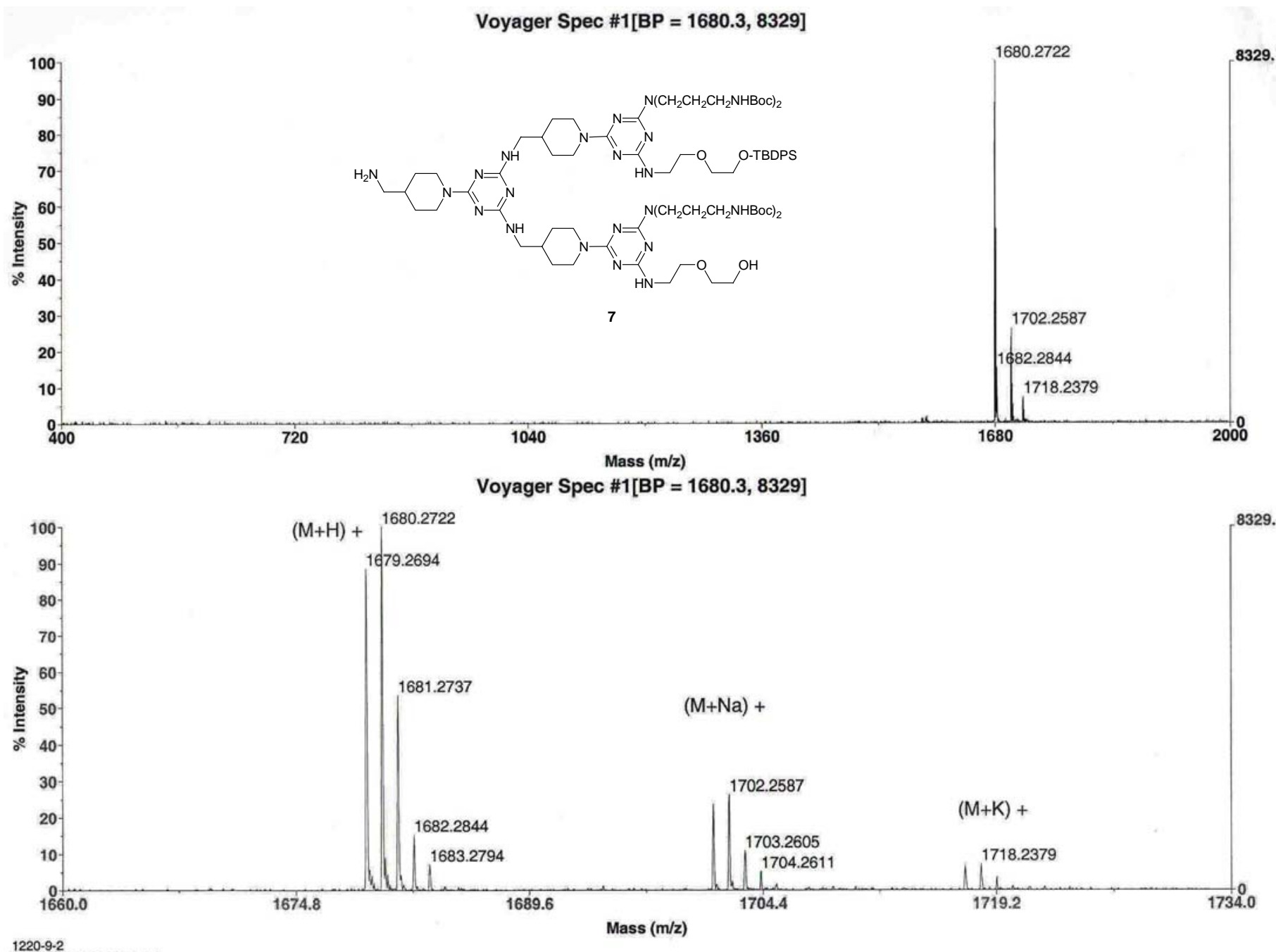

1220-9-2 0.112200406 0001.dat

Acquired: 12:57:00, December 20, 2004 


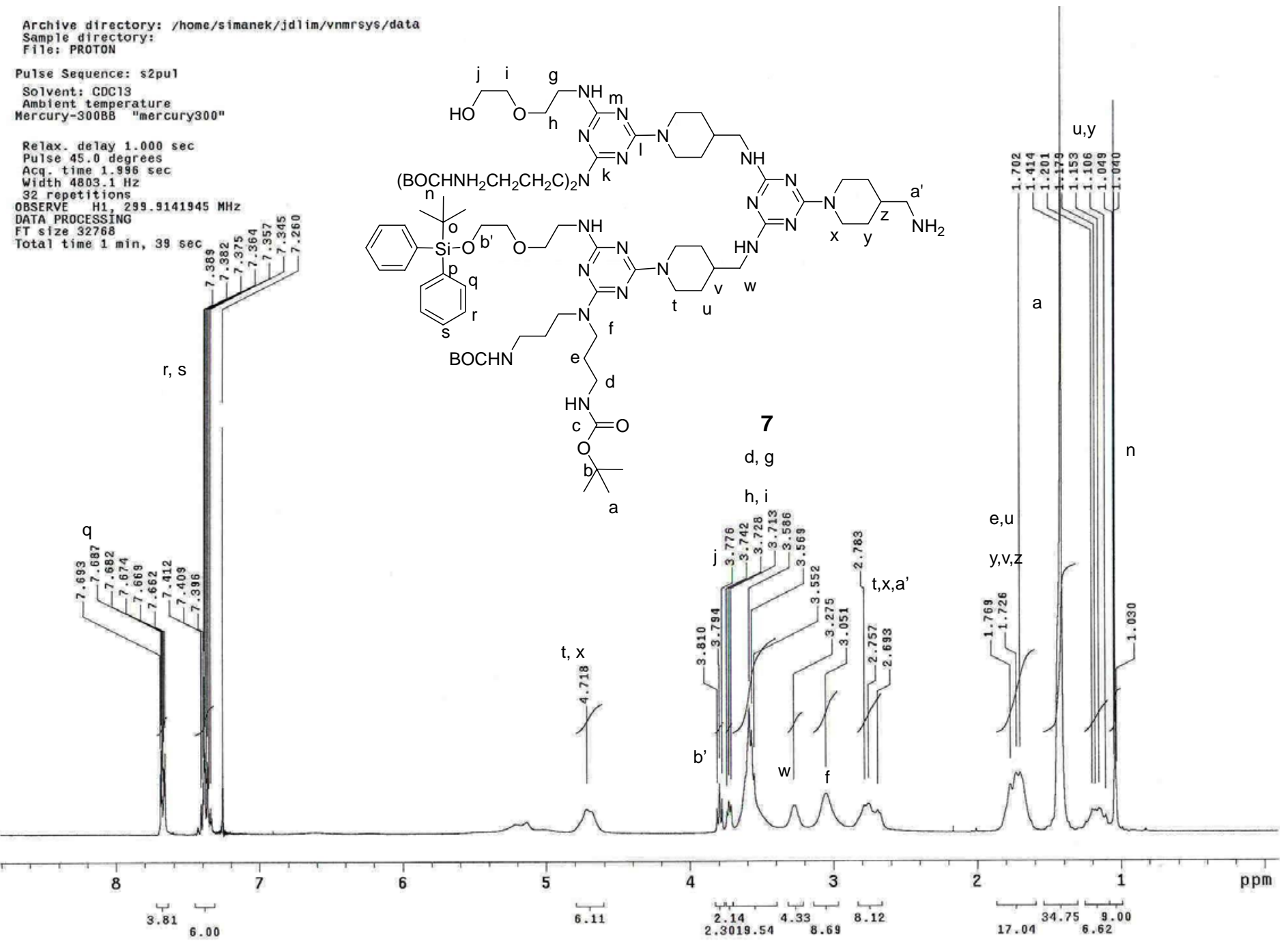


int 9

Pulse Sequence: s2pul

Solvent: cdc13
Ambtent temperature
Mercury-300BB "mercury $300 "$

Pulse 84.8 degrees
Acq. time $1.815 \mathrm{sec}$

Width $18761.7 \mathrm{~Hz}$

OBSERE C13, 75.4134738 MHZ
OECOULE H1, $299.9156550 \mathrm{MHZ}$

continuous Iy on
waLT-16 modulate

WATA PRocESSING
Dine broadening $1.0 \mathrm{H}$

Line broadenin

Total time $586 \mathrm{hr}, 42 \mathrm{~min}, 3 \mathrm{sec}$
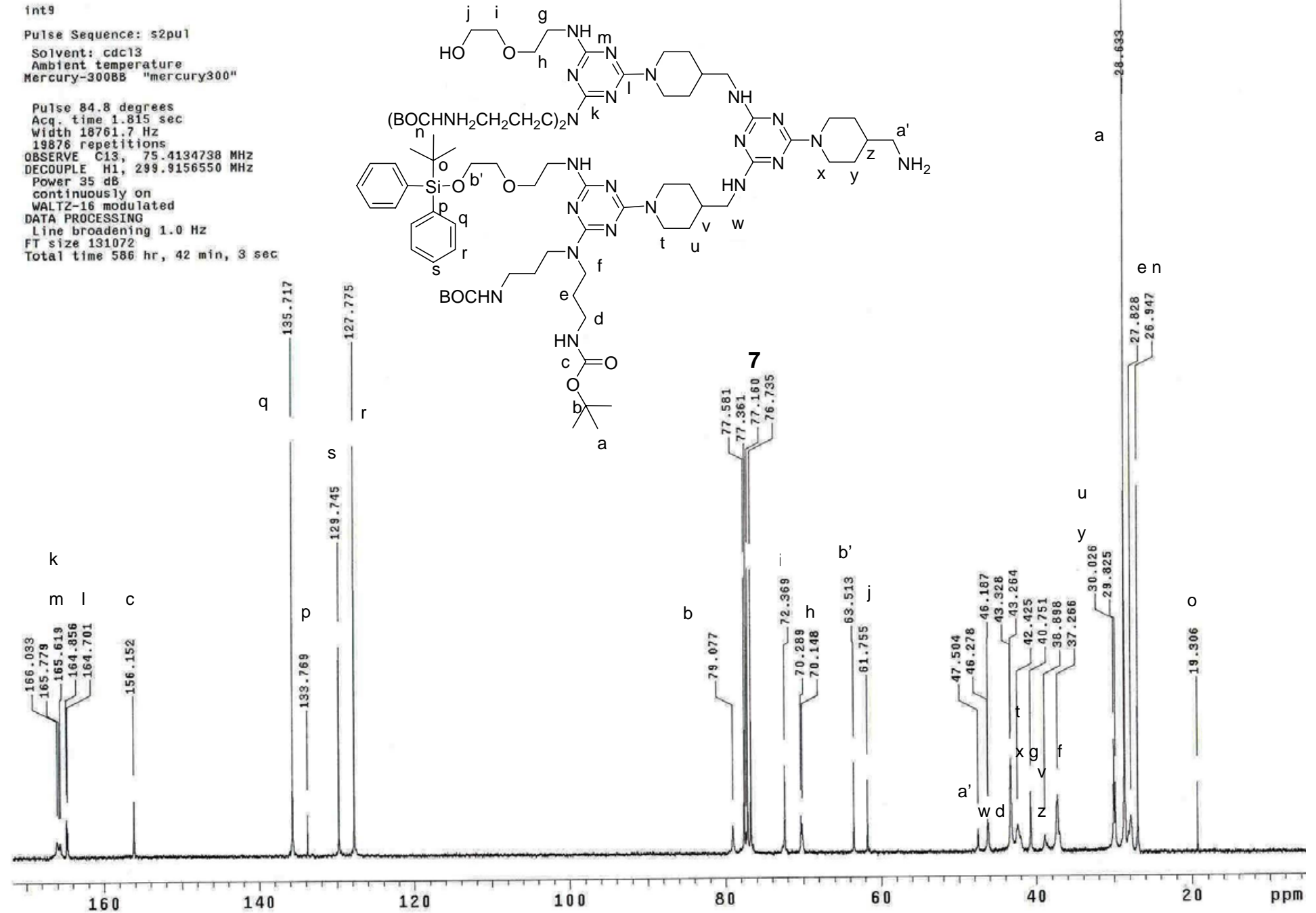
Voyager Spec \#1[BP = 3548.2, 2769]
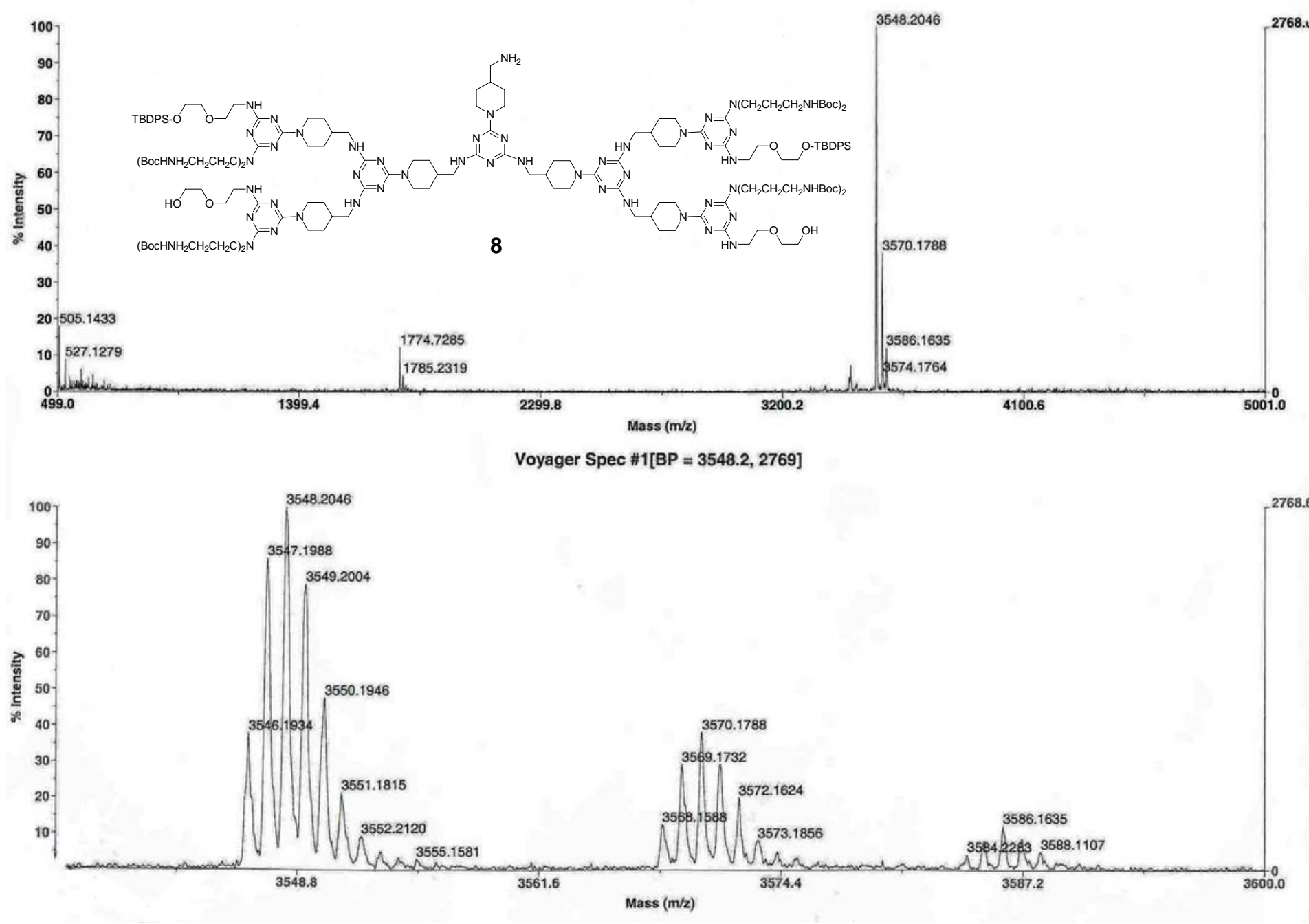


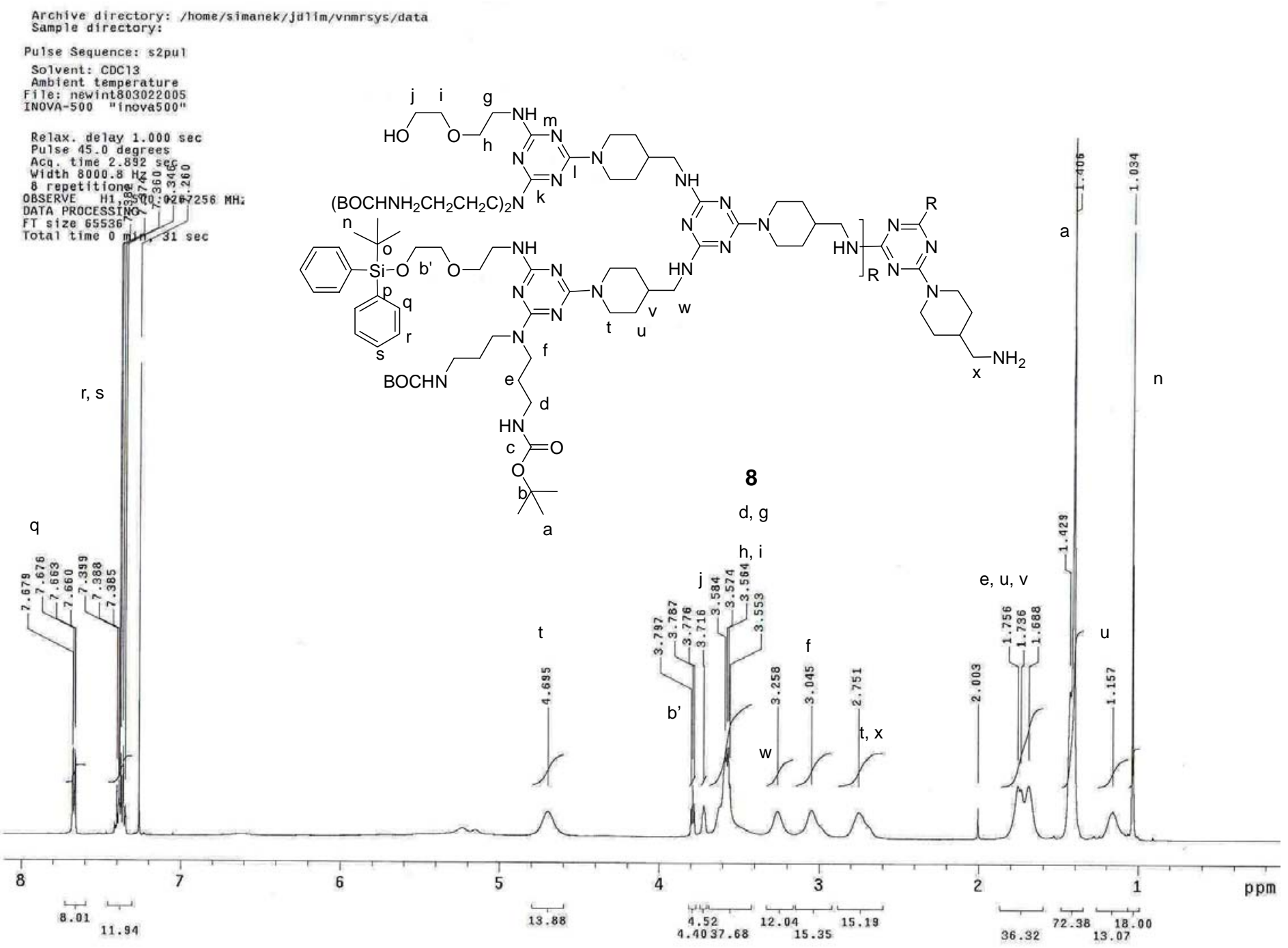




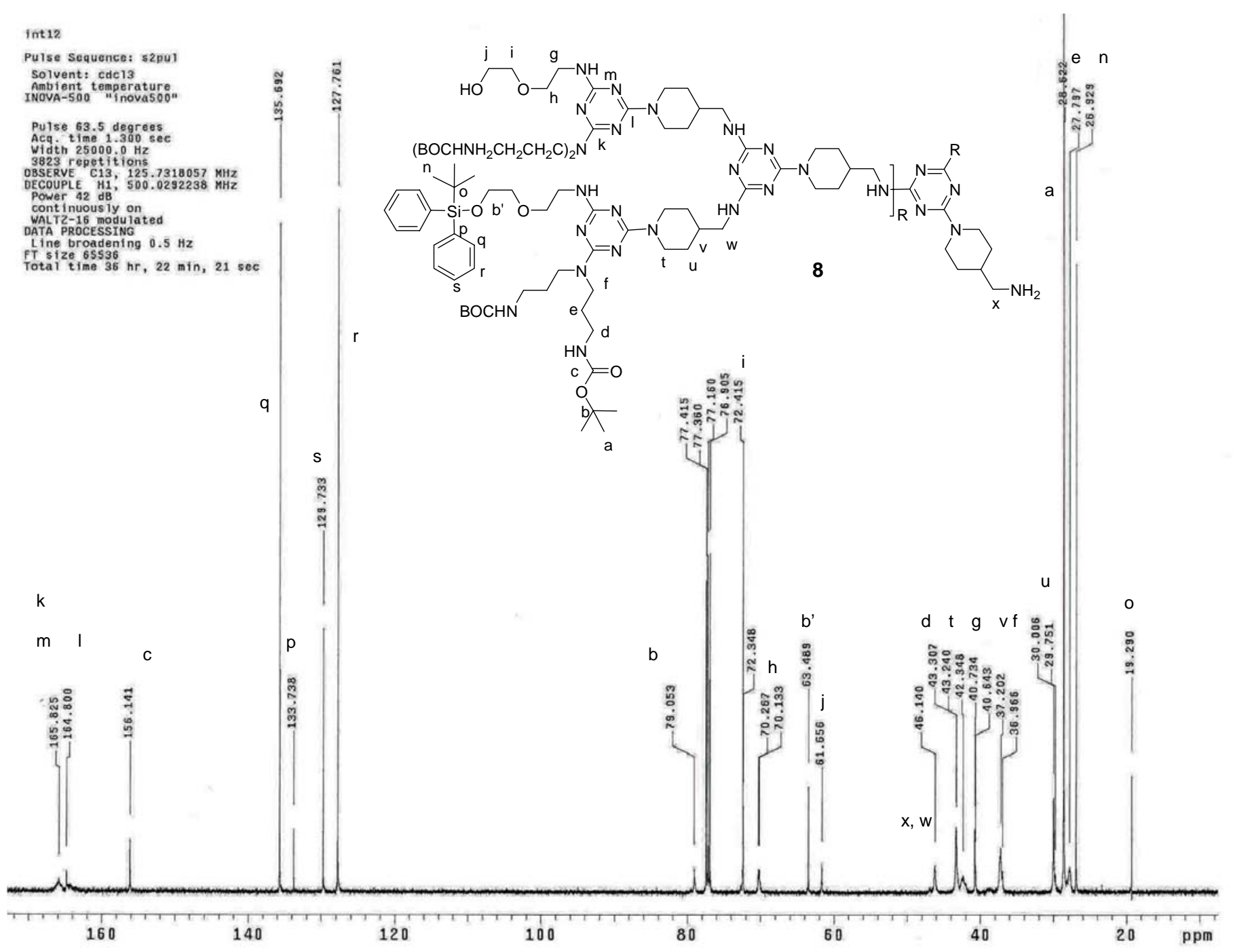


Voyager Spec \#1[BP = 593.1, 4698]
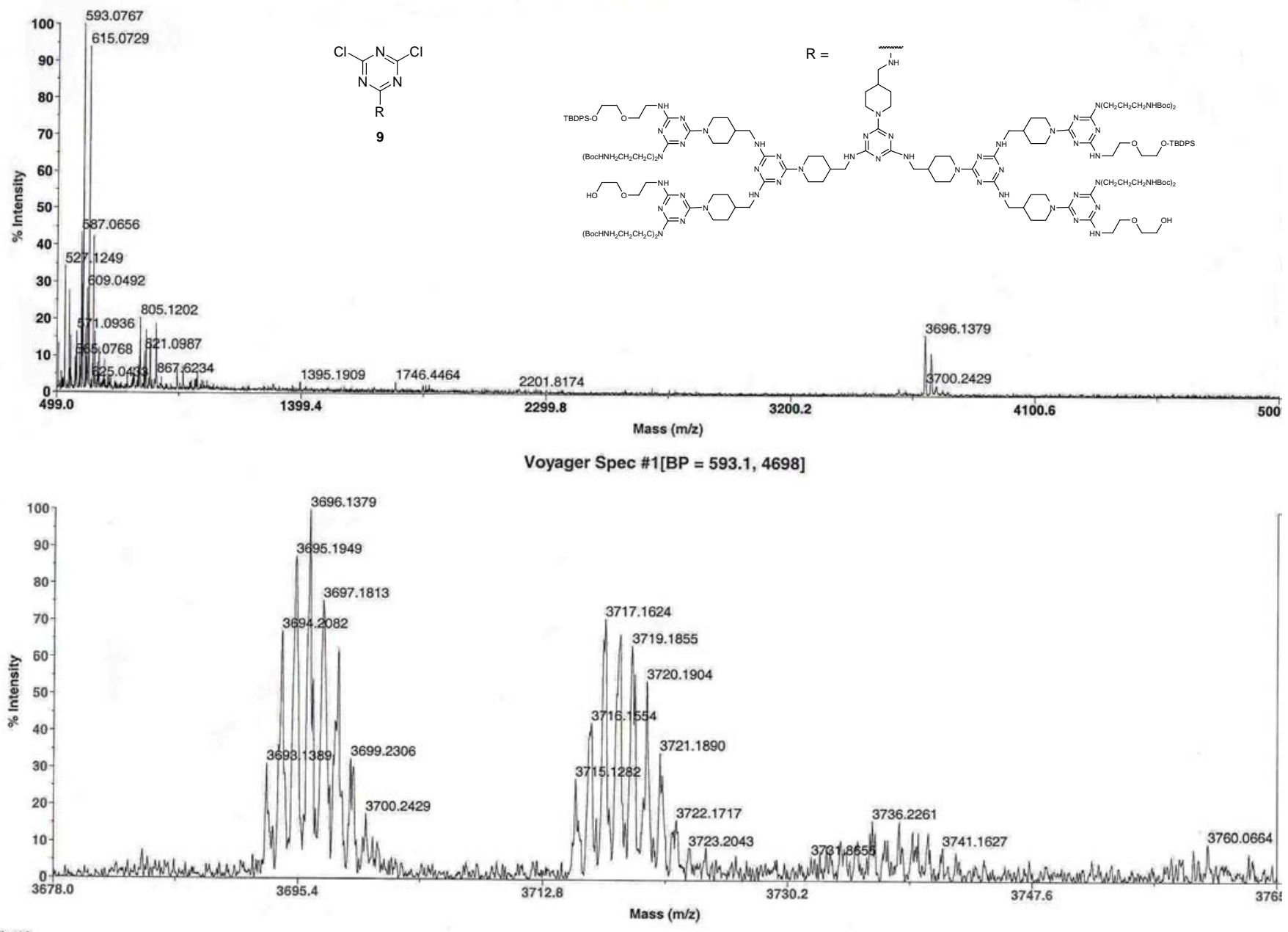

Dim13

Acquired: 11:53:00, January 19, 2005 


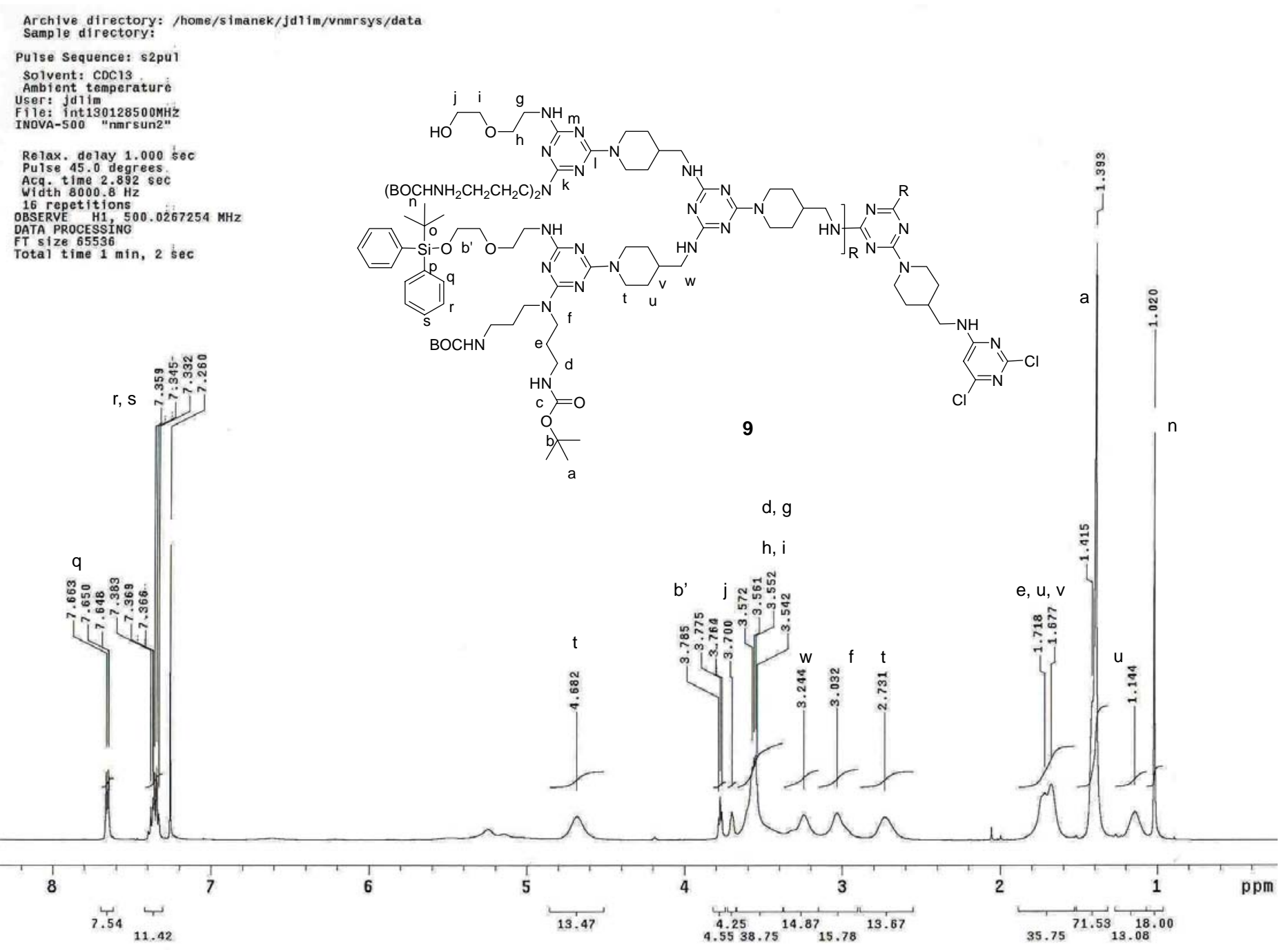




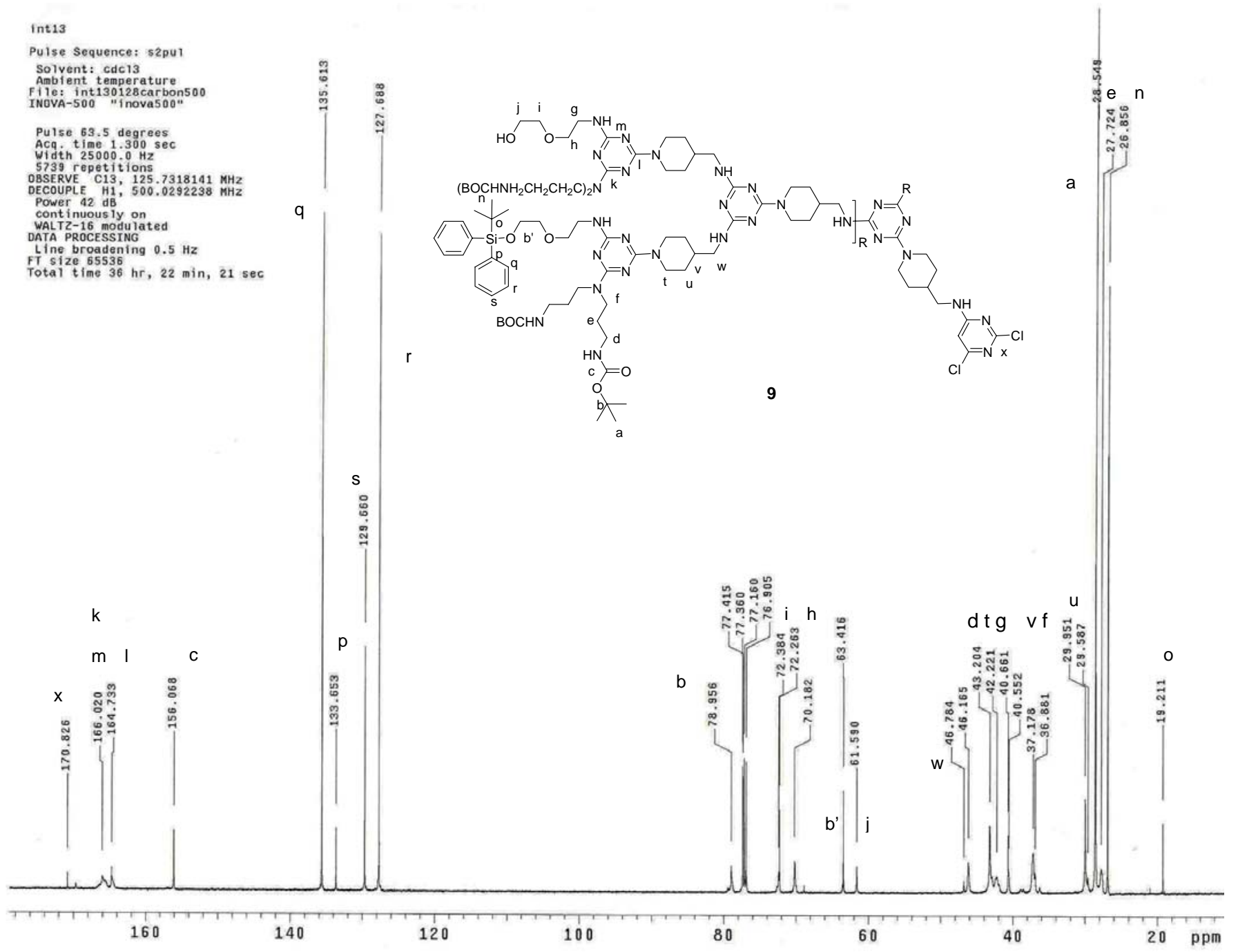



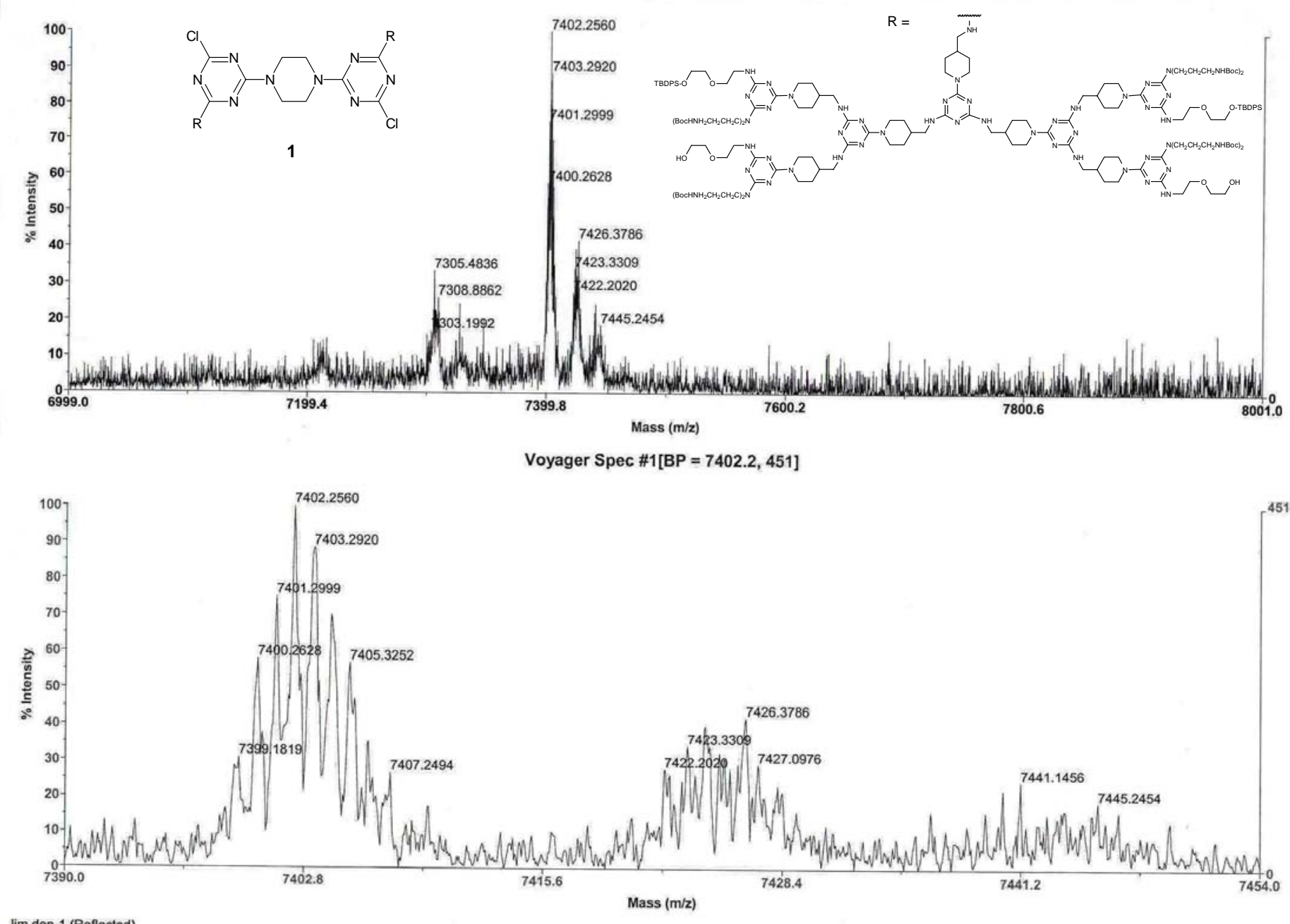

lim den-1 (Reflected)

Acquired: 14:12:00, January 27, 2005 


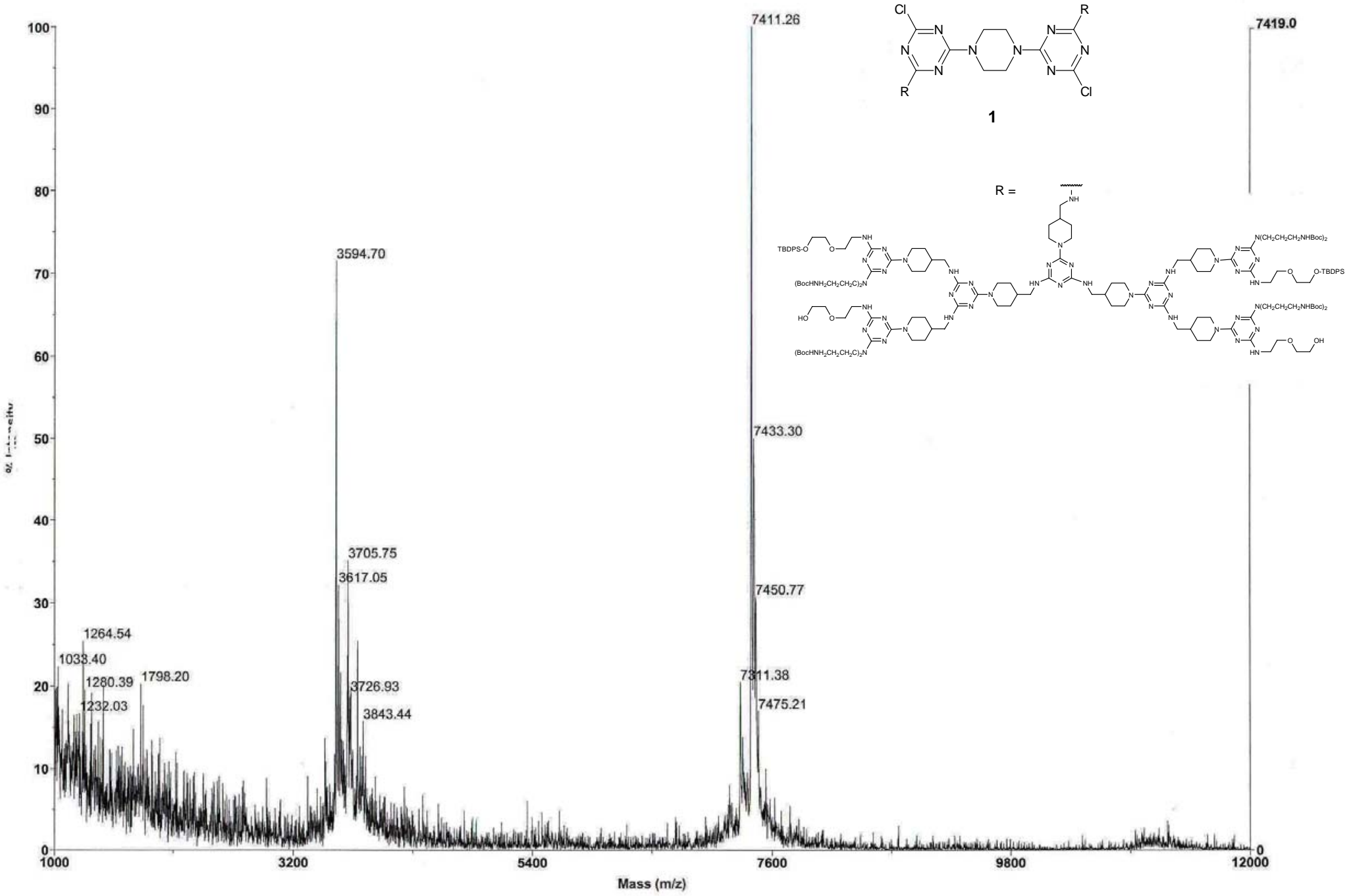




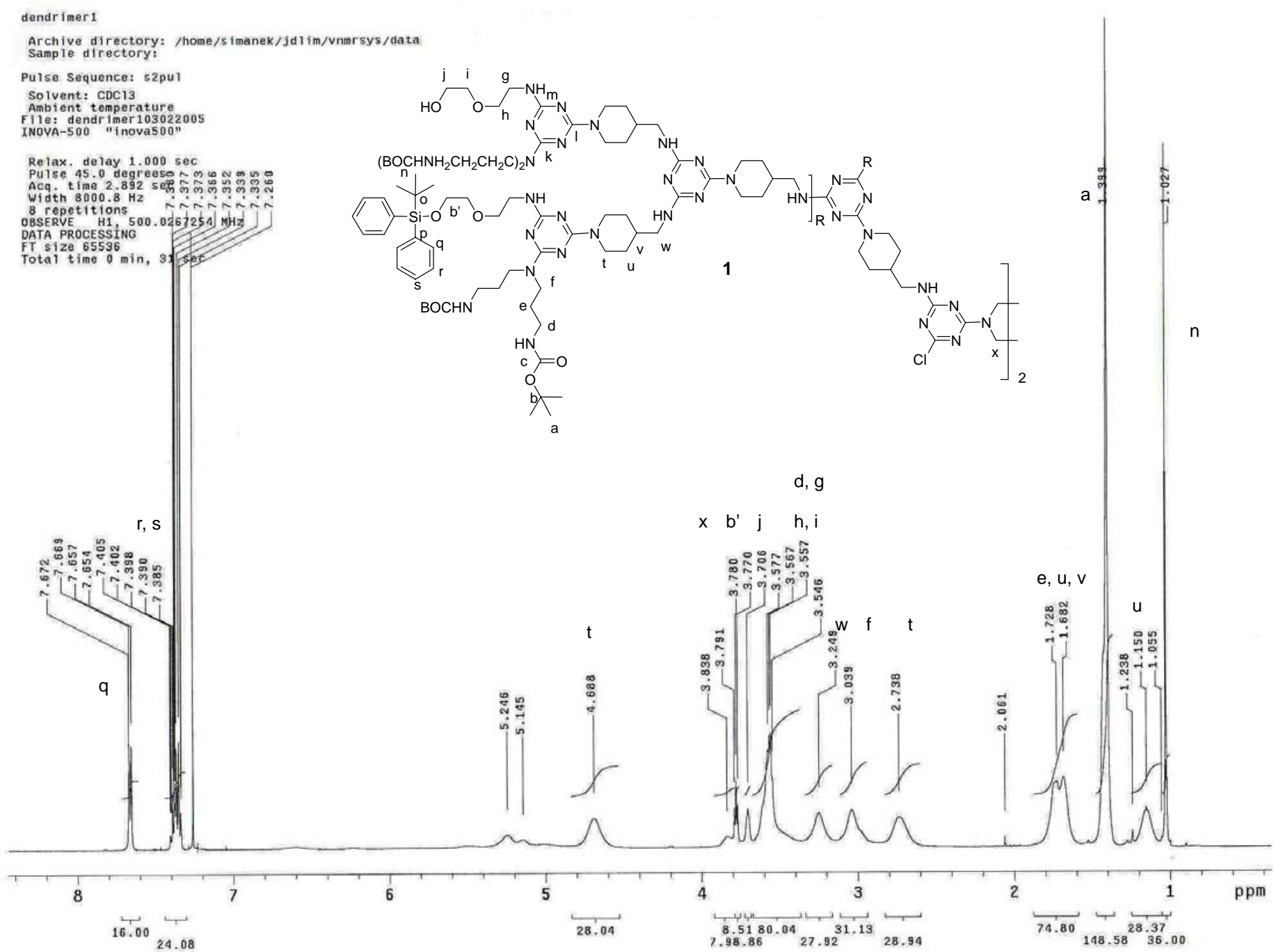


int14

Pu1se Sequence: s2pul Solvent: cdc13
Anblemt temperature
File: Nie: int 140130carbons
INOVA-500 "inova500"

Pulse 63.5 degrees
Acq. t ime 1.300 sec

Width $25000 ; 0$
20020
$20 p e t i t i$ OBSERE C13, 125.7318103 MHZ
DECOUPLE H1, 500.0292238 MHZ

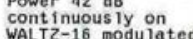

DATA PROCESSING $0.5 \mathrm{~Hz}$

FT size 655366 or, 0.5 Hz

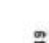

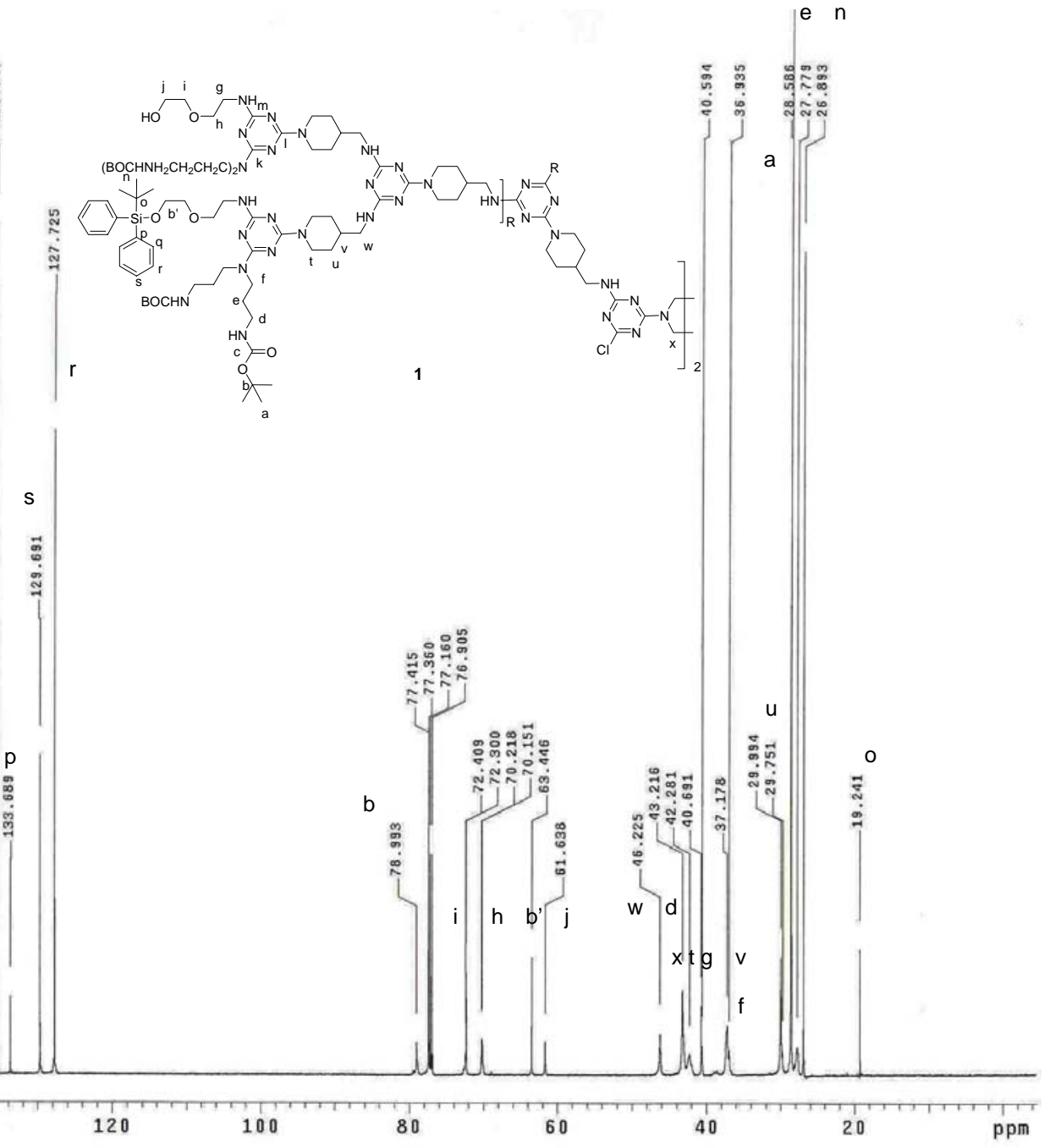



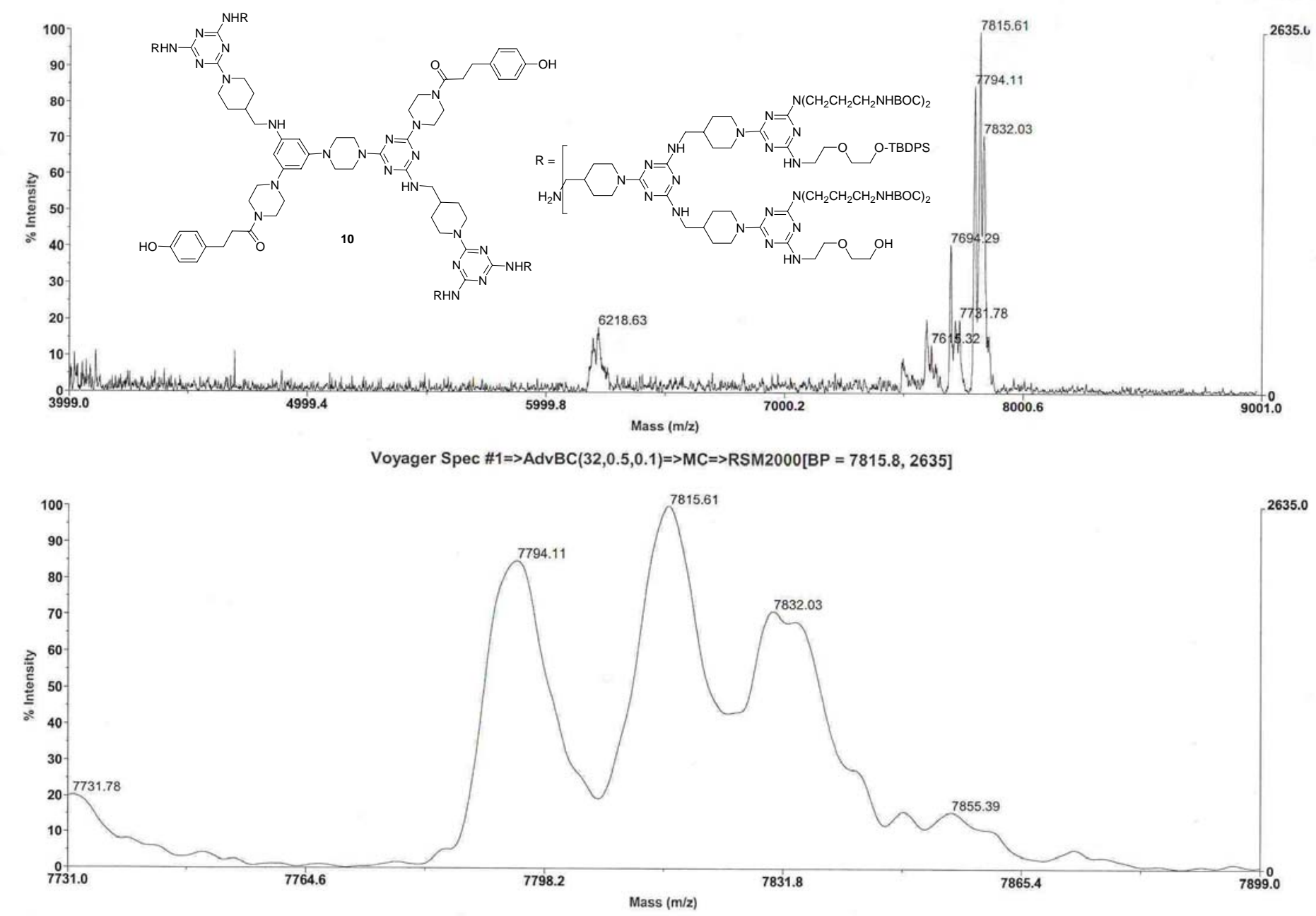

Den1-B-H

Dil...103160506 0001.dat
Acquired: 10:45:00, March 16, 2005 


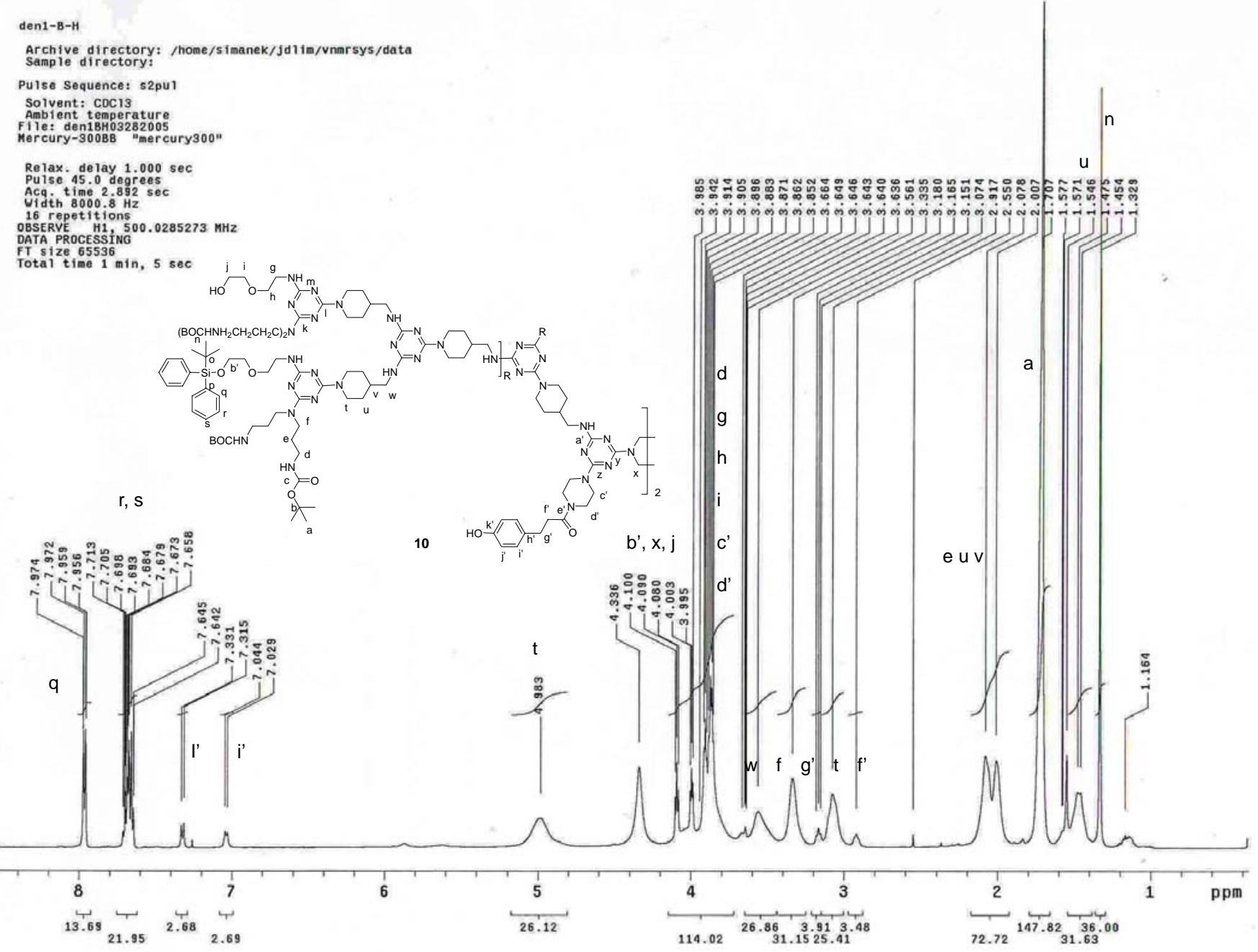




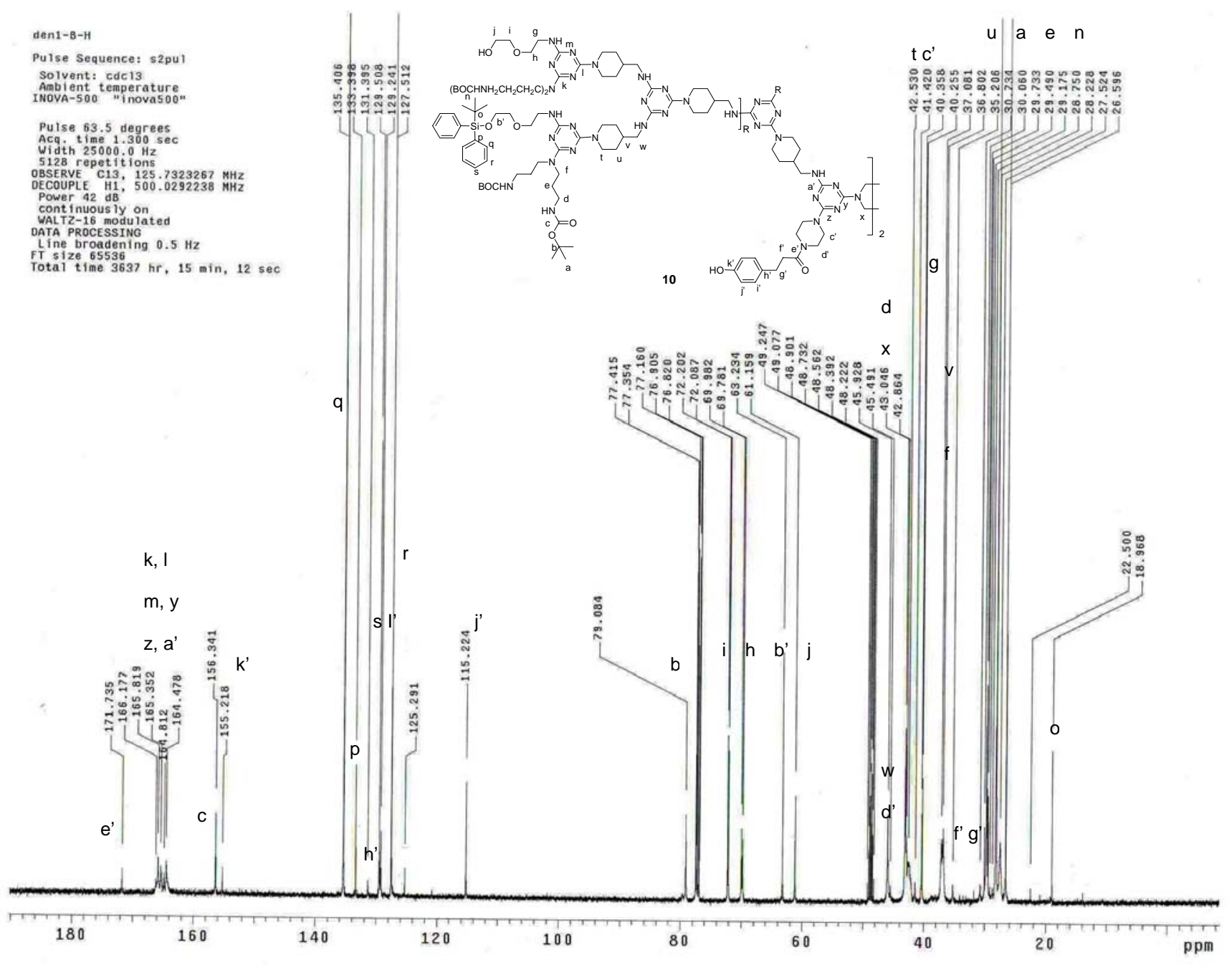




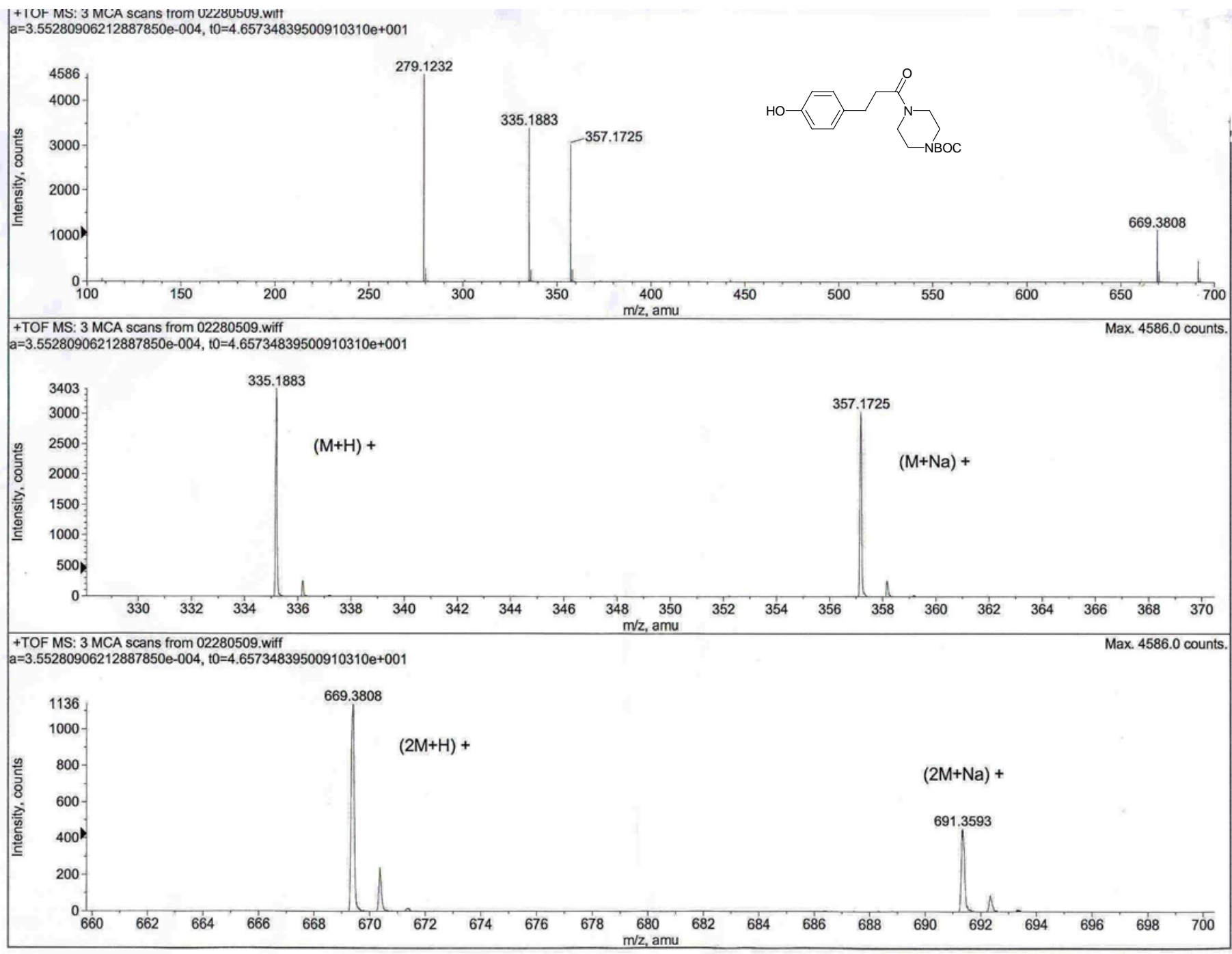




\section{B-H-Bocpiperazine}

Pulse Sequence: s2pul

Solvent: cdec13

Amberte temperature
File: BHbocpiperazine02262005
INOVA-500 "inovas00"

Relax. delay $1.000 \mathrm{sec}$
Pulse 70.0 degrees

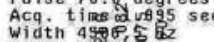

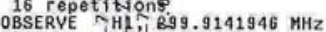

DATA PROCESSING
FT SIZZ 32788

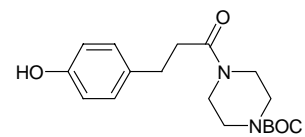

Total time $0 \mathrm{minh}, 48 \mathrm{sec}$

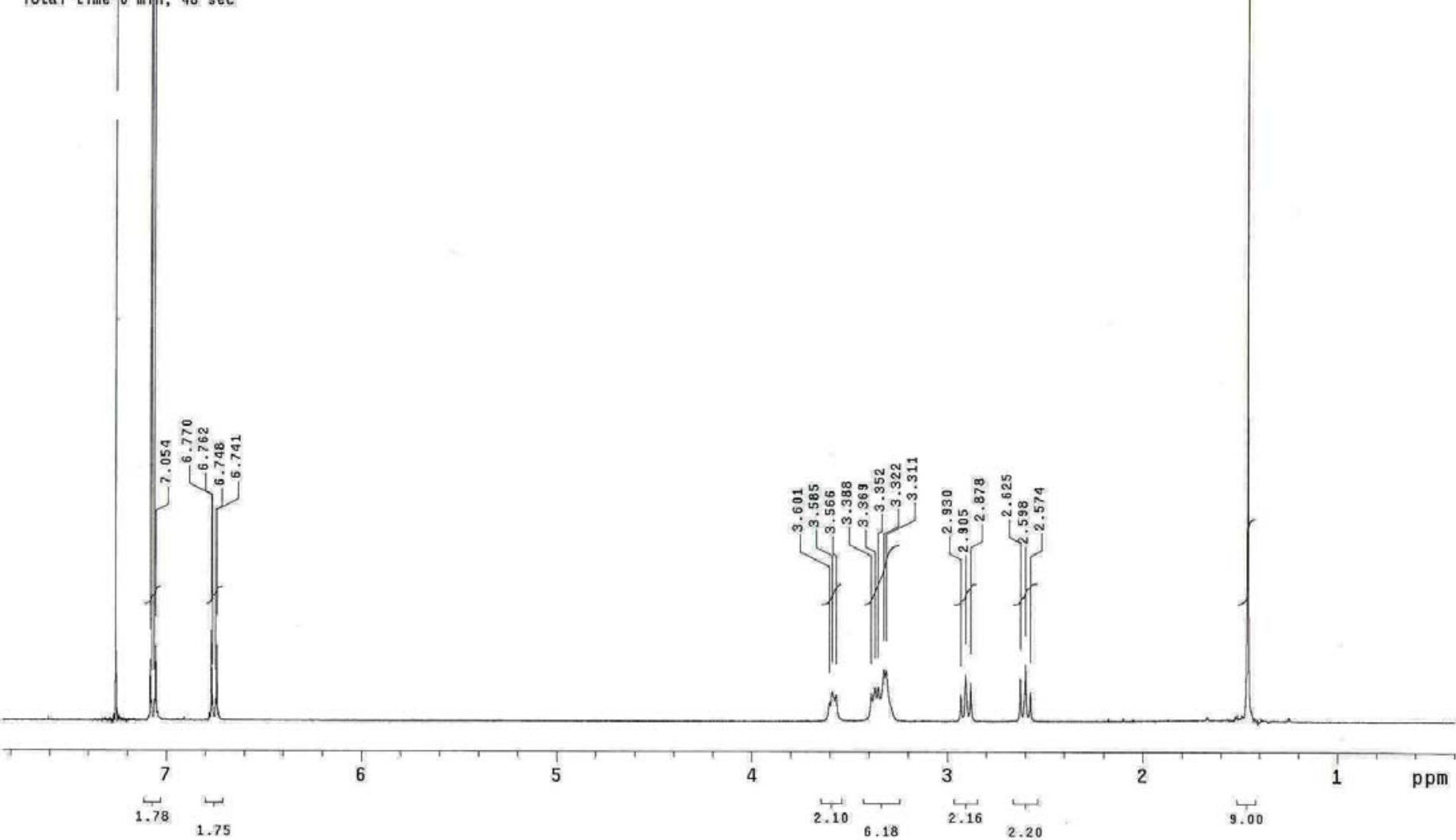




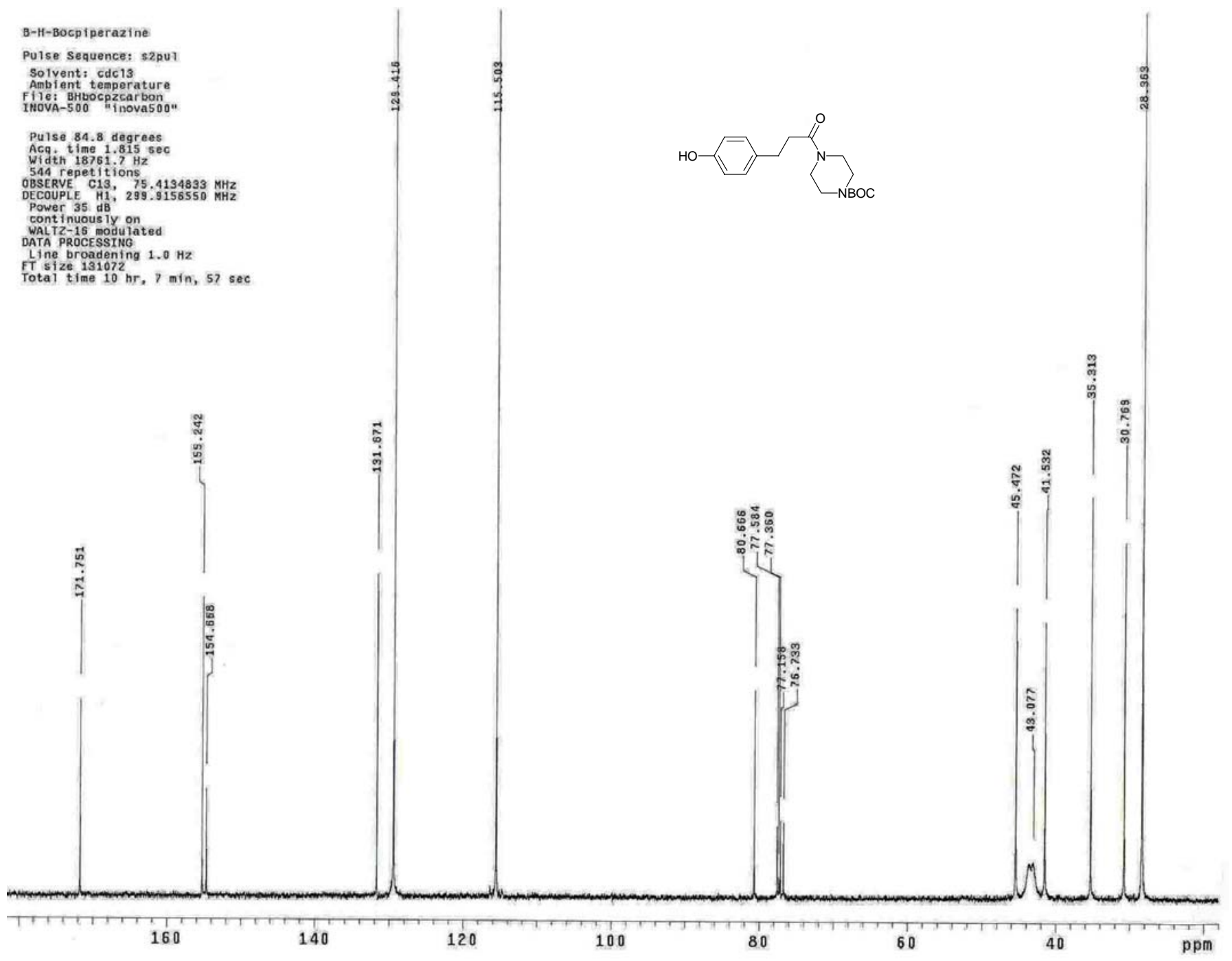




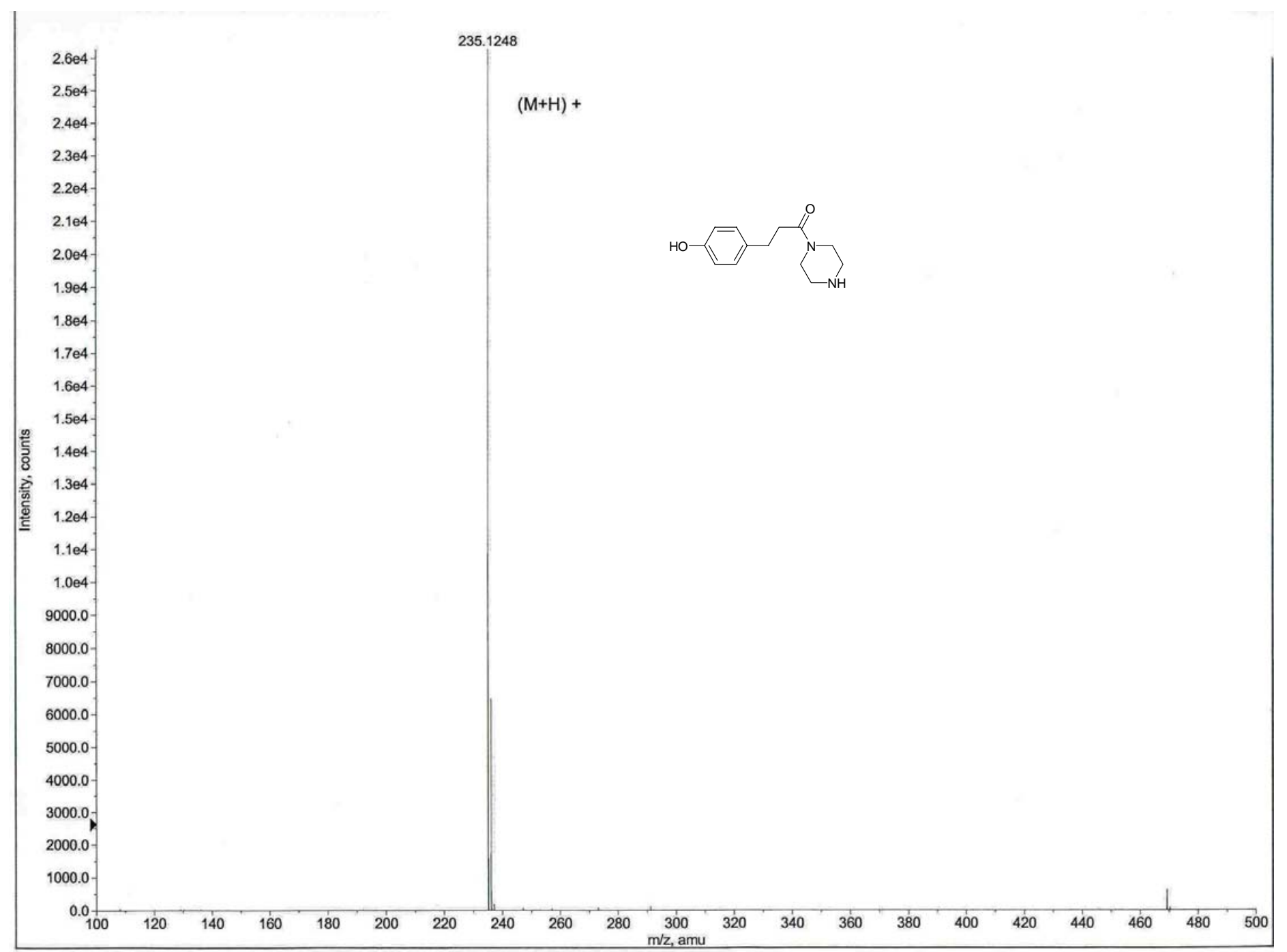


Puise Sequence: $\$ 2 p u$

Solvent: cd3od
Ambient temperatu

Fie: BHpiperazine 03012005
Fileva-500 "inovas

Relax. de lay $1.000 \mathrm{sec}$
Pulse 70.0 degrees

Acc. time $1.395 \mathrm{sec}$

Acidith $4506.5 \mathrm{~Hz}$
Wid

16 repetitions
OBSERVE H1, 299.9153745 MHZ

OBSERVE HIIT

Total time $0 \mathrm{~m} 1 \mathrm{n}, 48 \mathrm{sec}$
Total
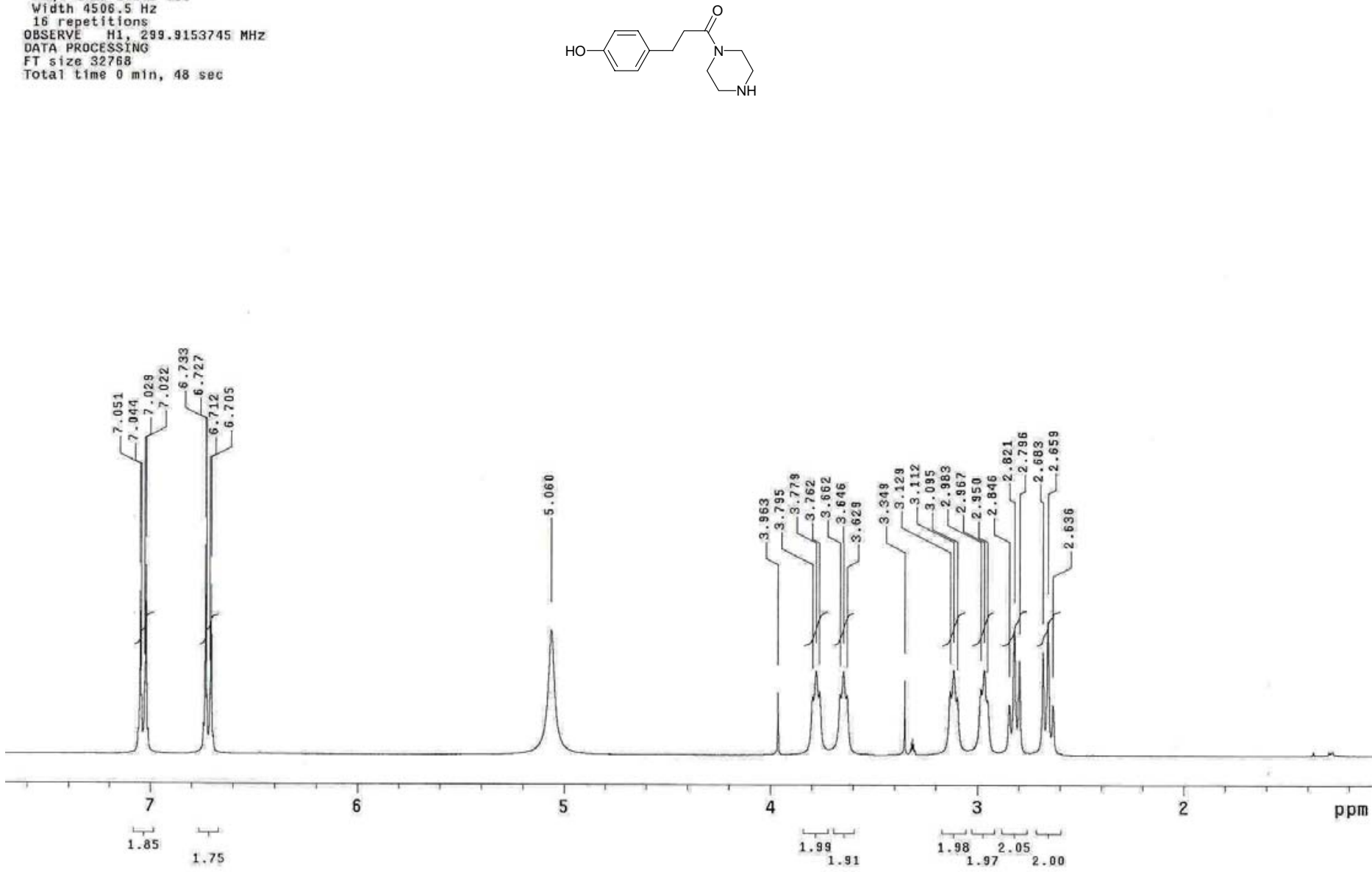
8-H-piperazine

Pulse Sequence: s2pul

Solvent: cd3od
Ambient temperature
Fille: BHpipazinecarbono301200

Pulse 84.8 degrees
Acq time 1.815 sec
Width $18761.7 \mathrm{~Hz}$

198 Repetitions
OBSERE C13, 75.4136791 HHZ
DECOUPLE H1, 299.9168366 MHZ

Power 35 dB
continuous y on
WALT Tz-16 modulat

Line broadening $1.0 \mathrm{~Hz}$

FT size $1310721.0 \mathrm{~Hz}$

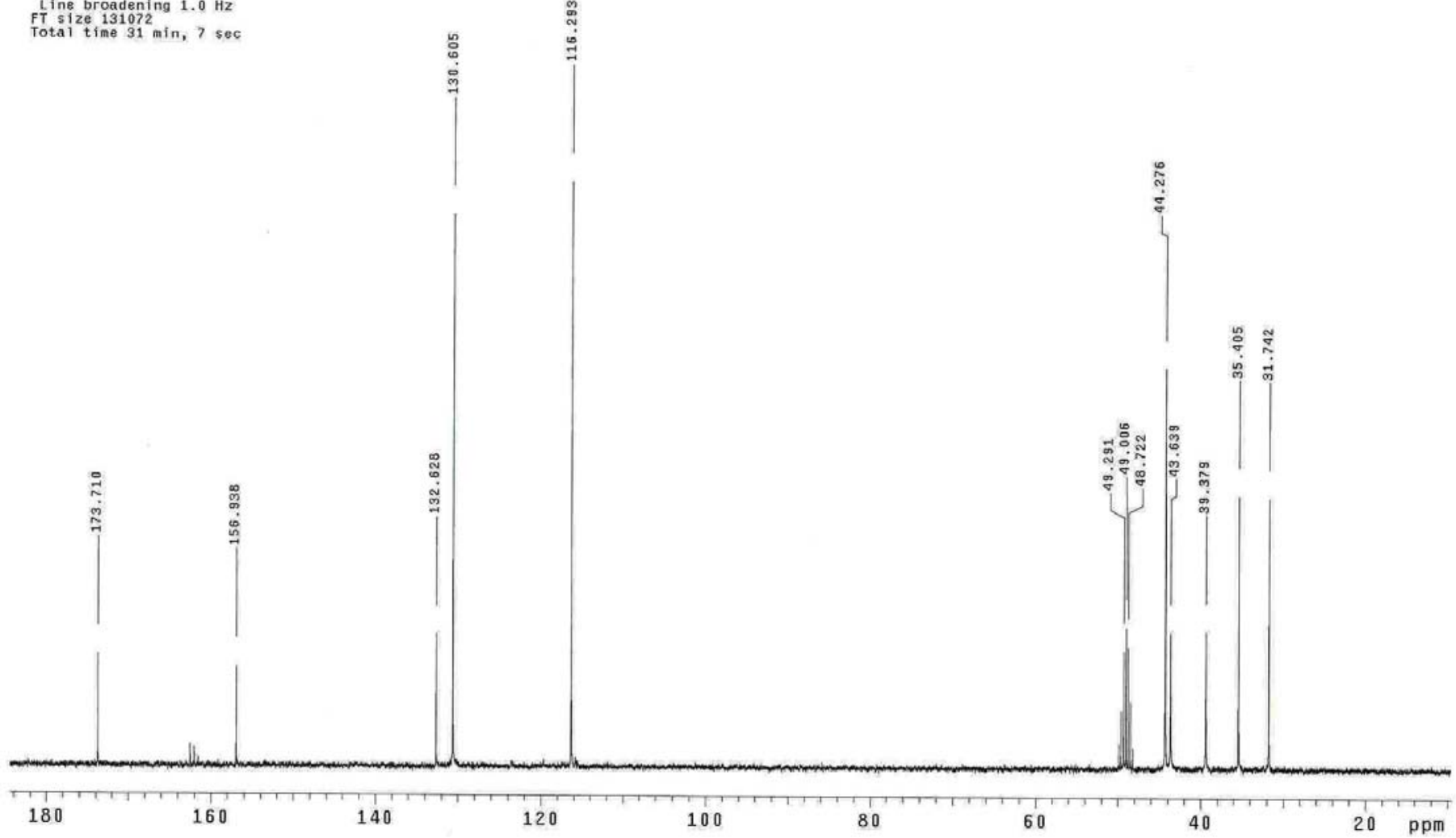

